TERRA. Revista de Desarrollo Local e-ISSN: 2386-9968

Número 6 (2020), 148-178

DOI 10.7203/terra.6.16680

IIDL - Instituto Interuniversitario de Desarrollo Local

\title{
La restauración de la torre del Zambullón (Motril, España): oportunidad para recuperar un Bien de Interés Cultural y favorecer el desarrollo local
}

\author{
José Ramón Sánchez Holgado \\ Dr. en Historia e Historia del Arte y Territorio \\ j.r.sanchez-holgado@hotmail.com \\ https://orcid.org/0000-0002-7017-7341
}

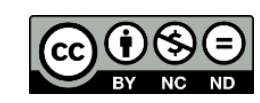

Esta obra se distribuye con la licencia Creative Commons Reconocimiento-NoComercial-SinObraDerivada 4.0 Internacional 


\title{
SECCIÓN ARTÍCULOS
}

\section{La restauración de la torre del Zambullón (Motril, España): oportunidad para recuperar un Bien de Interés Cultural y favorecer el desarrollo local}

Resumen: El patrimonio territorial constituye un recurso fundamental de explotación principalmente a escala local y comarcal, que le puede proporcionar con unos objetivos definidos y las estrategias adecuadas diferentes posibilidades de promoción cultural, natural y turística. Con la intención de realzar y poner en valor la torre del Zambullón (término municipal de Motril, Andalucía, España), se realizó una intensa búsqueda documental que nos ha permitido conocer su pasado y junto a unas imprescindibles jornadas de campo, analizar sus posibilidades de integración en la sociedad de la que forma parte. Una vez presentadas unas propuestas generales de intervención y teniendo en cuenta las conclusiones alcanzadas, este estudio de investigación tiene la convicción de que con una restauración adecuada, se conseguiría la recuperación por su temática de un bien de interés cultural único en la costa granadina, contribuyendo de forma simultánea al desarrollo territorial sostenible.

Palabras clave: Geografía de la Memoria, Cartografía, Interpretación del Patrimonio, Paisaje Cultural.

\section{The restoration of the Zambullón tower: opportunity to recover an Asset of Cultural Interest and promote local development}

\begin{abstract}
Territorial heritage constitutes a fundamental resource whose exploitation, with defined objectives and with the appropriate strategies, can provide different possibilities of cultural, natural and tourist promotion, mainly at local and regional level. With the intention of enhancing and assessing Zambullón tower (Motril, Andalucía, Spain), an intense documentary search and field days have been carried out, which have allowed us to know its past and analyze its possibilities of integration in the society of which it is part. Once some general proposals for intervention have been presented and taking into account the conclusions reached, this research study has the conviction that with an adequate restoration, the recovery of a good of unique cultural interest in the Coast of Granada would be achieved, contributing simultaneously to sustainable territorial development.
\end{abstract}

Key words: Geography of Memory; Mapping; Heritage Interpretation; Cultural Landscape.

Recibido: 15 de febrero de 2020

Devuelto para revisión: 15 de abril de 2020

Aceptado: 22 de mayo de 2020

\section{Referencia / Citation:}

Sánchez, J. R. (2020). La restauración de la torre del Zambullón (Motril, España): oportunidad para recuperar un Bien de Interés Cultural y favorecer el desarrollo local. TERRA. Revista de Desarrollo Local, (6), 148-178. DOI 10.7203/terra.6.16680 
IDEAS CLAVE / HIGHLIGHTS / IDEES CLAU

1. Durante siglos, el uso de torres y atalayas para la custodia del territorio resultó habitual en la cuenca mediterránea.

2. Este sistema defensivo tuvo una gran incidencia en la costa granadina, con su propio Reglamento promulgado por Carlos III.

3. Durante el siglo XIX, salvo las fortalezas reutilizadas para los nuevos requerimientos de seguridad, el resto se abandonó.

4. En la actualidad, la mayoría de las fortalezas de la costa granadina están protegidas por la figura de Bien de Interés Cultural.

5. Con una intervención adecuada e integración en la oferta patrimonial cultural, contribuirían a la dinamización del territorio.
1. For centuries, the use of towers and watchtowers to guard the territory was commonplace in the Mediterranean basin.

2. This defensive system had a great impact on the coast of Granada, with its own regulations promulgated by Carlos III.

3. During the 19th century, except for the fortresses that were reused for the new security requirements, the rest were abandoned.

4. At present, most of the fortresses on the Granada coast are protected by the figure of Asset of Cultural Interest.

5. With appropriate intervention and integration in the cultural heritage offer, they would contribute to the dynamization of the territory.
1. Durant segles, l'ús de torres i talaies per a la custòdia del territori va resultar habitual en la conca mediterrània.

2. Aquest sistema defensiu va tindre una gran incidència a la costa granadina, amb el seu propi Reglament promulgat per Carles III.

3. Durant el segle XIX, excepte les fortaleses reutilitzades per als nous requeriments de seguretat, la resta es va abandonar.

4. En l'actualitat, la majoria de les fortaleses de la costa granadina estan protegides per la figura de Bé d'Interés Cultural.

5. Amb una intervenció adequada i integració en l'oferta patrimonial cultural, contribuirien a la dinamització del territori. 


\section{INTRODUCCIÓN}

La costa granadina se ha caracterizado durante siglos por ser un lugar poco seguro donde residir, ya que resultaban relativamente habituales los ataques, agresiones y capturas de sus vecinos provenientes de corsarios y piratas berberiscos procedentes del $\mathrm{N}$ de África. Durante la Edad Media, entre los siglos XIII-XV, la cuestión de su defensa se entendió como un objetivo básico de estabilidad para el Emirato Nazarí, de ahí que ya comenzaran a organizarse de forma relativamente coordinada las rudimentarias fortalezas, asociadas a las alquerías y aquellos otros núcleos poblacionales más expuestos a los peligros y del que afortunadamente se conservan interesantes ejemplos como los castillos de Salobreña y Almuñécar o las torres del Granizo y la Rijana.

Al estar profundamente determinada por los factores fisiográficos que le imprimían la secuencia continuada de $\mathrm{O}$ a $\mathrm{E}$ de las sierras de Almijara, Los Guájares, Lújar y La Contraviesa produjo un asilamiento respecto a la capital del reino. Este hecho motivó a partir del siglo XVI que se tuviera que desarrollar un sistema defensivo propio, que otorgara las garantías oportunas de seguridad e incentivara el asentamiento en un territorio hasta entonces entendido como hostil para la vida cotidiana e imprescindible en su puesta en explotación, por los recursos que atesoraba y que podrían contribuir en el mantenimiento de los elevados gastos que se generaban (Velasco, 2019) (Figura 1).

Figura 1. Los acantilados de Calahonda-Castell de Ferro y la torre del Zambullón desde el mar

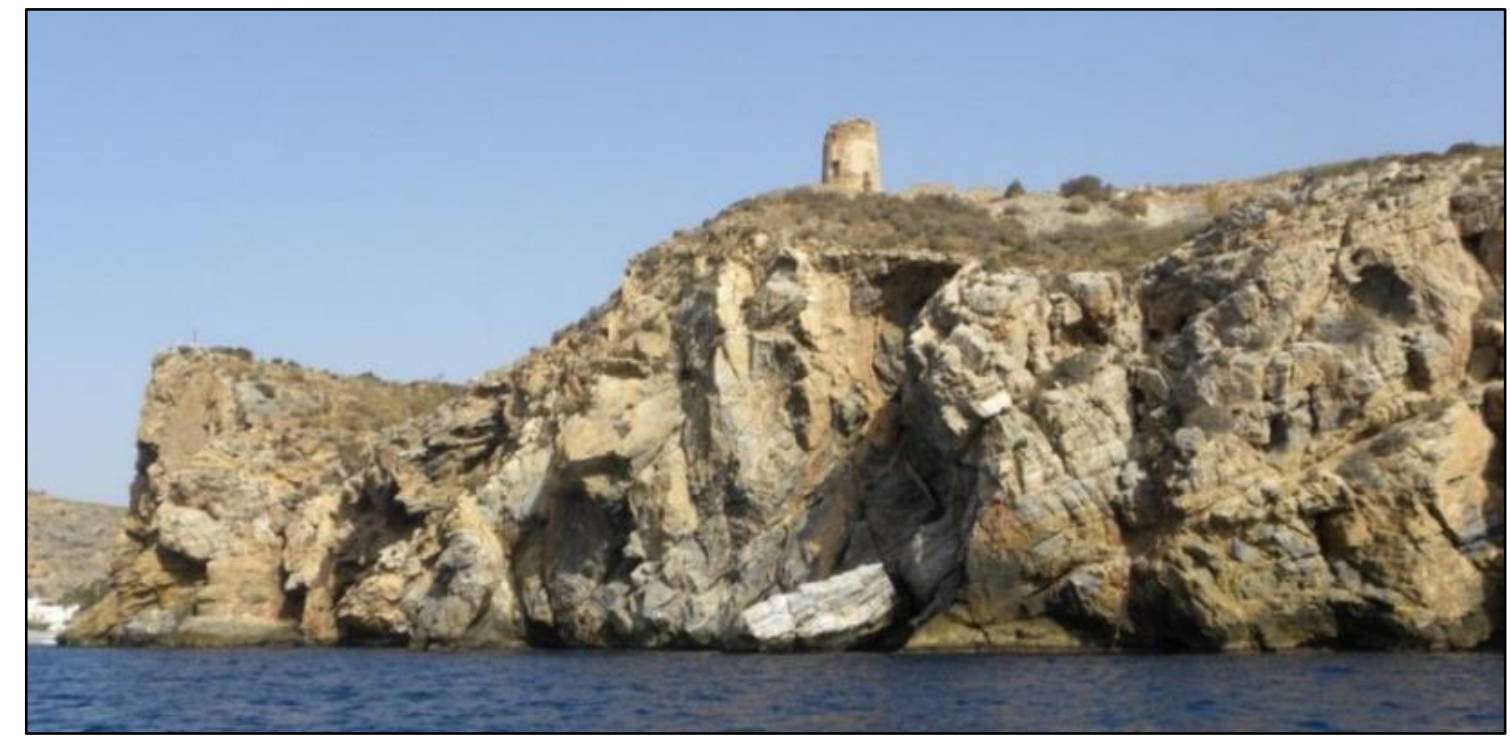

Fuente: José Ramón Sánchez Holgado, imagen captada el día 16 de agosto de 2016.

De ahí que, hasta bien entrado el siglo XVII y fruto de la vulnerabilidad existente, esta franja costera se encontraba bastante despoblada y los escasos asentamientos que se conservaban, debían de encontrarse necesariamente al resguardo de alguna fortificación defensiva (Lorenzo y Ayala, 2006) o bien disponer de un espacio amplio desde el litoral que produjera cierta ventaja a los residentes en los casos de huida. En muchos ejemplos, los agresores eran plenamente conocedores de la demarcación a la que se dirigían ya que entre sus aliados se encontraba población musulmana que ya había residido previamente en este sitio (García-Consuegra, 2017). 
Desde el inicio del establecimiento de este complejo sistema defensivo, la protección de las inmediaciones donde se sitúa la torre del Zambullón se consideró fundamental por su potencial geoestratégico al resguardo y abastecimiento de las embarcaciones que hacia esta margen del mar Mediterráneo se dirigían. Básicamente como estancia del personal encargado de la custodia de su posición, con el nombre de Cala del Arena o Cala del Harena y a posteriori, ya plenamente identificada mediante la construcción de su correspondiente fortaleza como torre de Cala Onda, Calahonda, Puntalón, Condenada o Zambullón (Posadas, 1996; Gil, 2004; Sánchez, 2018) e integrada en el desarrollo normativo para la ejecución de los servicios como fueron la Instrucción dada por los Reyes Católicos para la guarda de la costa de 1497 y el Reglamento que su Majestad Carlos III mandó observar en las diferentes clases destinadas al real servicio de la costa del Reino de Granada de 1764.

Con esta situación geopolítica y social, el presente estudio de investigación desarrollará distintas acciones con el objetivo final de alcanzar la puesta en valor del conjunto y que necesariamente transcurre por un análisis territorial e histórico previo, profundizando a continuación en las relaciones cartográficas y despachos militares que determinaron la evolución y transformación de la fortificación según las necesidades del momento; para finalizar con una comparación de la situación actual junto unas conclusiones que incluyan unas propuestas de actuación que favorezcan el alcance de nuestro propósito principal.

\section{CONTEXTO GEOGRÁFICO E HISTÓRICO}

La torre del Zambullón, catalogada como bien de interés cultural ${ }^{1}$, se localiza en un sector escarpado y acantilado en el extremo $\mathrm{O}$ del límite territorial del término municipal de Gualchos (Comarca Costa Tropical de Granada) y en las últimas estribaciones de la Sierra de Lújar (Cordilleras Béticas) que desembocan directamente sobre el mar. La longeva confluencia entre el mar y la montaña ha configurado de forma determinante el relieve litoral granadino, otorgándole un paisaje propio donde se sucede la alternancia de áreas abruptas e inaccesibles con otras llanas asociadas a las calas que coinciden con las desembocaduras de barrancos y ramblas (Gómez y Fábregas, 1996).

Esa singularidad territorial ha determinado que en los últimos años se le haya proporcionado de diferentes figuras de atención medioambiental propias, destacando en ellas el reconocimiento en la diversidad ecológica que se localizan en los acantilados y fondos marinos de Calahonda-Castell de Ferro $^{2}$ y que se extiende entre los términos municipales de Motril y Gualchos o la conservación de las diferentes clases de hábitats que conviven en la sierra de Castell de Ferro ${ }^{3}$.

Relativamente próximo a la torre del Zambullón y aprovechando la finalización en dirección $\mathrm{O}$ de la zona pedregosa y acantilada, siempre a refugio de las fuertes e inestables mareas se situó un antiguo embarcadero natural que se caracterizó por la profundidad de

\footnotetext{
${ }^{1}$ En el Catálogo General del Patrimonio Histórico Andaluz, Consejería de Cultura y Patrimonio Histórico, Junta de Andalucía, se identifica mediante el código R.I.-51-0011742-00000, en su tipología jurídica como monumento.

2 Natura 2000. Código del lugar ES6140014, nombre del lugar: Acantilados y fondos marinos de Calahonda-Castell de Ferro, Institución que suministra la información: Dirección General de Planificación, Consejería de Medio Ambiente, Junta de Andalucía.

${ }^{3}$ Natura 2000. Código del lugar ES6140011, nombre del lugar: Sierra de Castell de Ferro, Institución que suministra la información: Dirección General de Planificación, Consejería de Medio Ambiente, Junta de Andalucía.
} 
sus fondos formados por cantos y arenas sometidos a la acción del oleaje (Jabaloy et al., 2008) y del inicio de la conocida playa de Calahonda (término municipal de Motril).

Estas peculiaridades geográficas favorecieron que durante años se convirtiera en el único muelle comercial de la costa granadina hasta alcanzar el año 1883, cuando se desestimó por otro emplazamiento en Varadero, más cercano al atrayente foco económico y poblacional de Motril ${ }^{4}$. Y la misma proyección que hasta entonces había alcanzado el puerto de Calahonda en concordancia al desarrollo de sus actividades comerciales y marítimas, se extendió al embrionario núcleo poblacional que en sus alrededores se asentó (Figura 2).

Figura 2. Acantilados de Calahonda-Castell de Ferro, con la fortificación del Zambullón al fondo

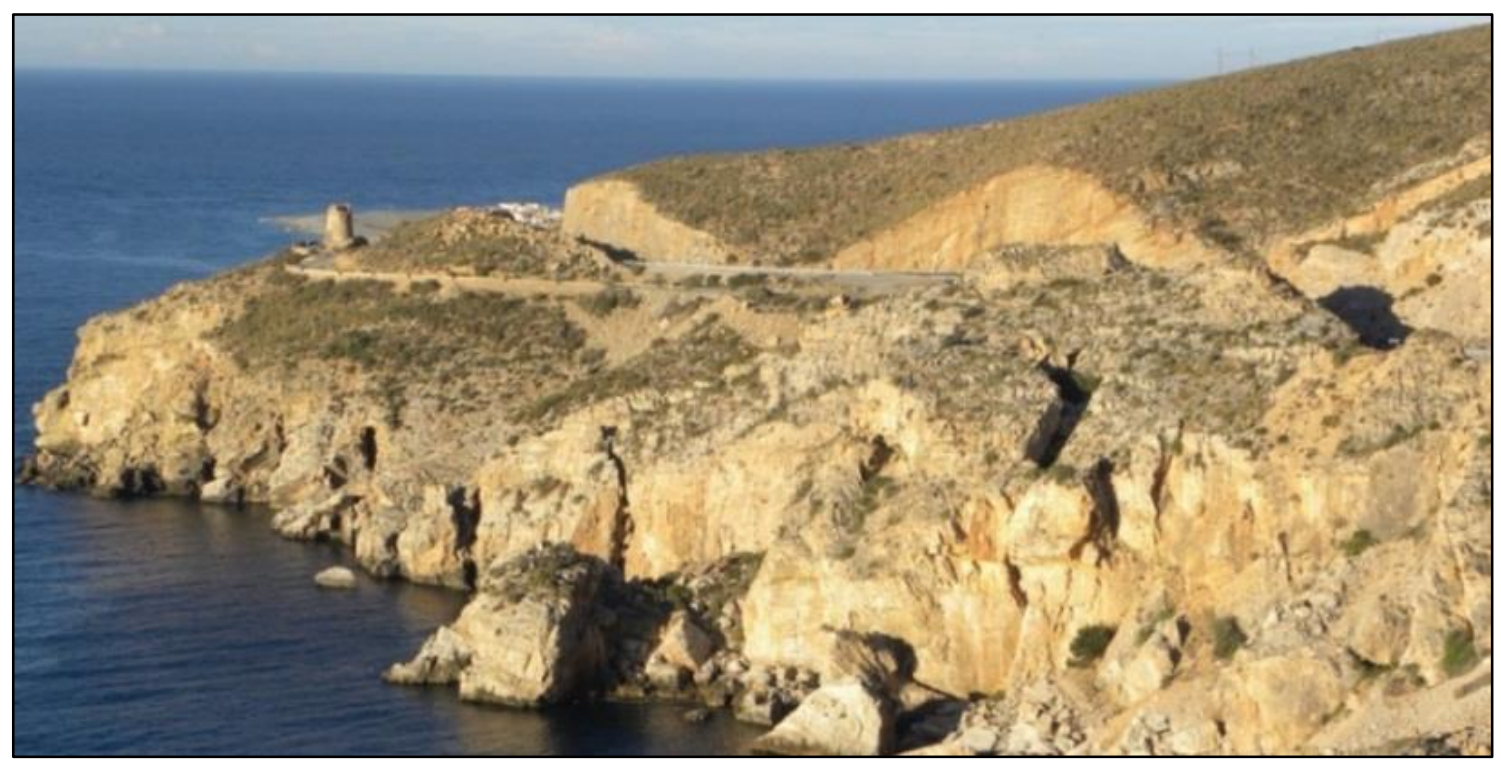

Fuente: José Ramón Sánchez Holgado, imagen captada el día 16 de agosto de 2016.

Y este hecho, evidentemente no pasó inadvertido para los encargados de la ejecución del complejo sistema defensivo, ya que no solo tuvieron que revisar las necesidades más inmediatas al incipiente eje económico y social, sino extenderlas a las fortificaciones siguientes. Así, la torre del Zambullón en dirección E tenía continuidad de servicio con las torres y atalayas de La Rijana (cronología medieval) y Estancia (siglo XVIII) hasta alcanzar el castillo de Castell de Ferro (cronología medieval). Mientras que, hacia el $\mathrm{O}$ hacía lo propio con la atalaya del Llano de Carchuna (siglo XVI), la fortaleza abaluartada de Carchuna (siglo XVIII) y las torres del Chucho (cronología medieval) y Torrenueva (siglo XVIII); estas últimas posiblemente con dedicación preferente a la custodia de la extensión que comprendía la longeva explotación salinera ${ }^{5}$.

\footnotetext{
${ }^{4}$ Se desconoce si por Real Orden se pudo habilitar algún otro punto de la costa granadina para el embarque y desembarque de determinados productos que se autorizaban para este tipo de disposiciones administrativas.

5 Por su localización, el reducto fortificado de Calahonda (tipología jurídica monumento, código R.I. 510012236-00000) resulta anterior al periodo defensivo que se trata en el presente estudio de investigación y que la construcción de la atalaya del Llano de Carchuna, teniendo en cuenta las modificaciones fisiográficas y territoriales experimentadas, pudo ratificar su estratégica elección y sustitución en sus funciones defensivas.
} 


\section{RECOPILACIÓN CARTOGRÁFICA Y DOCUMENTAL}

Siguiendo un criterio cronológico documental, la primera referencia expresa a nuestro ámbito de estudio queda registrada a través de la Relación de la visita que realiza Antonio de Berrío y Luís Machuca a la costa del Reino de Granada durante el año $1571^{6}$, señalando que la estancia de la Cala del Harena se encontraba desierta, si bien, solía tener dos guardas. En la misma descripción resaltan la importancia de construir una fortificación en la punta de la cala que podría ofrecer seguridad a un tramo muy hondable y frecuentado por enemigos.

A raíz de esta revista inicial y mediante Relación sobre las torres que se han de hacer y las que están hechas conforme a la visita de Antonio de Berrío y Luís Machuca a la costa del Reino de Granada de fecha 29 de diciembre de $1575^{7}$, se propone levantar otra torre encima de la Cala del Arena que amplíe el perímetro de garantía hacia Cala Onda, destinándose seiscientos ducados. El Informe de Bartolomé Amphoux sobre el estado de las fortificaciones de la costa del Reino de Granada de 8 de octubre de $1726^{8}$, resalta el buen estado que presenta las seis torres que se sitúan entre los castillos de Salobreña y Castil de Ferro: la Torre de la Mar de Motril, la Torre Nueva, la Torre de Trafacasil, la Torre del Llano, la Torre de Calahonda y la Torre de la Reycana. Y de la Relación y visita a la costa del Reino de Granada hecha por el Mariscal de Campo Marqués de Valdecañas de 24 de noviembre de $1739^{9}$, identifica la Torre de Cala Honda a un cuarto de legua de la Torre del Llano y que todo su distrito de vigilancia estaba compuesto por playa.

En el Informe sin firma sobre el estado de las fortificaciones existentes en la costa del Reino de Granada de 12 de septiembre de $1759^{10}$ se sugiere de forma inédita realizar unas modificaciones notables en su estructura, consistiendo en la apertura de su parapeto de dos cañoneras para colocar dos cañones y levantar un tabique de dos pies de alto y siete varas de largo para cubrir su plataforma de un cerro inmediato que la enfila. Igualmente se propone colocar el palo de la escala por la parte interior, ascendiendo todo lo presupuestado a un importe de ciento y cincuenta reales.

De la Relación de Antonio María Bucarelli y Ursúa sobre el estado de las fortificaciones de la costa de los Reinos de Granada y de Murcia hasta Cartagena de 15 de febrero de $1762^{11}$, señala que la Torre de Calahonda dista un cuarto de legua de la Torre del Llano de Carchuna, encontrándose situada sobre una altura de peña viva, pudiendo tener dos cañones de a ocho y que se encuentra en mediano estado, con una dotación personal de dos torreros y tres soldados de infantería. En el mismo documento se vuelve a destacar el riesgo de la playa rasa que se sitúa a poniente por su facilidad que otorga a los desembarcos y de los peligros que suponen los desembarcos de moros, llegando a los cortijos de dos leguas tierra adentro y se propone que con una mayor vigilancia se podrían cultivar las tierras del llano, que se caracterizan por su fertilidad y quizás al abrigo de las fortificaciones, se podría formar algún pueblo.

\footnotetext{
${ }^{6}$ A.G.S.G.A.: Leg. 74, d. 120.

${ }^{7}$ A.G.S.C.C.: Leg. 2177, s.n.

${ }^{8}$ A.G.S.G.M.: Leg: 3686, s.n.

${ }^{9}$ I.H.C.M.C.G.D.: LEG. 4-5-2-3.

${ }^{10}$ A.G.S.G.M.: Leg. 3415, s.n.

${ }^{11}$ A.G.S.G.M.: Leg. 3687, s.n.
} 
La Relación general de Esteban Aymerick sobre el estado de las fortificaciones de la costa del Reino de Granada de fecha 12 de octubre de $1765^{12}$, afirma que para poder montar en su explanada dos cañones de a 8 se le debe crear una sobrebóveda del grueso de un ladrillo y encima un pie de hormigón, formándose su lugar común, recalzarlas por partes y repellarla. Y del Plan general de obras de José Crame de 18 de diciembre de $1767^{13}$, recuerda que para poder instalar los dos cañones de a 8 de su dotación se necesita redoblar su bóveda de un ladrillo de grueso y cuatro de pulgadas de hormigón, repellar, ripiar y revocar sus paredes.

Figura 3. Plano y perfil del proyecto de construcción para dotar de dos cañones de a 16 en su dotación, del año 1770

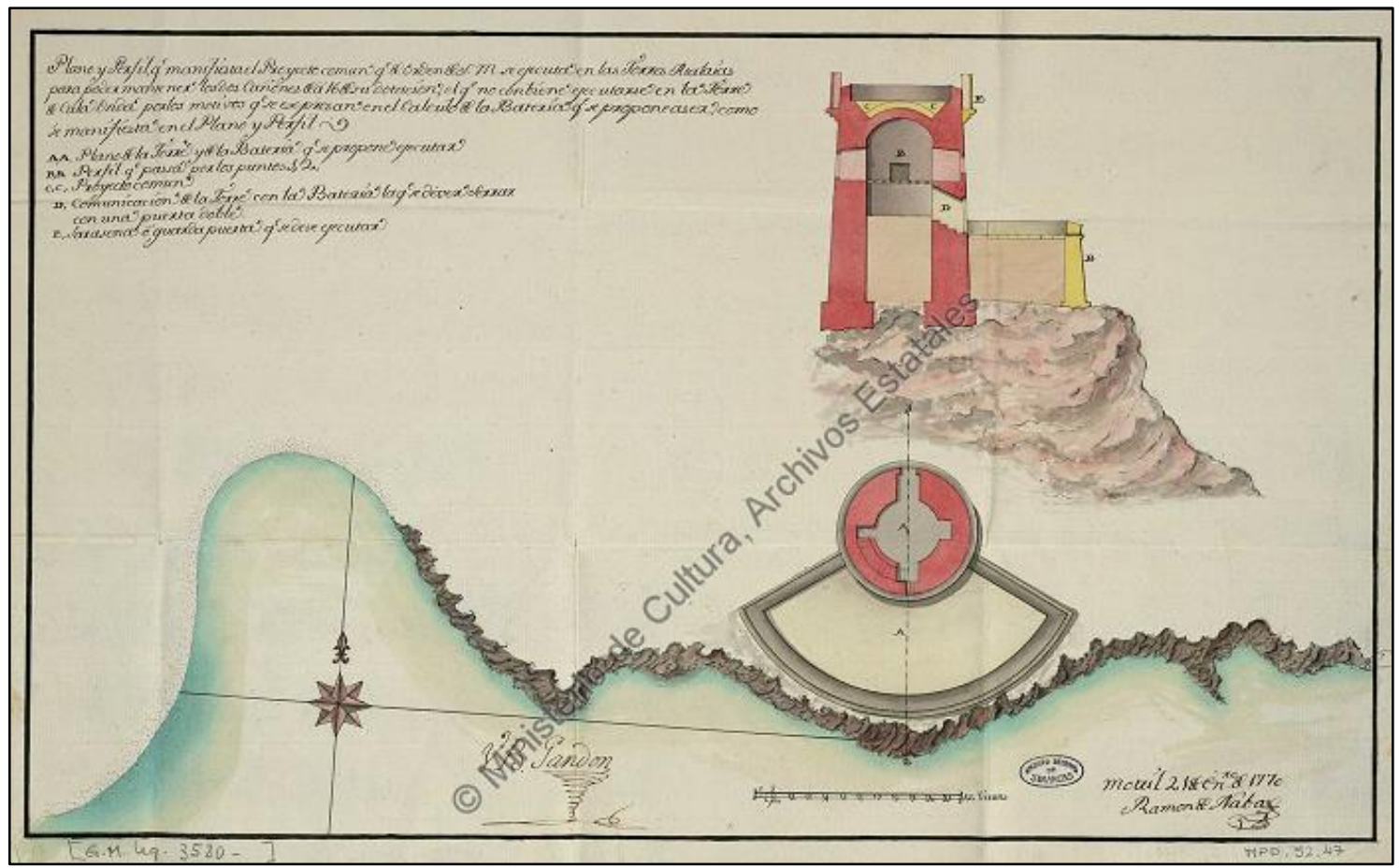

Fuente: España. Ministerio de Educación, Cultura y Deporte. Archivo General de Simancas. MDP, 52, 047. Ubicación Anterior: SGU, 03580. http://www.mcu.es/ccbae/es/consulta/registro.cmd?id=183781

El mapa histórico del año 1770 resulta de extraordinario interés, ya que su materialización denota un rico y plural conocimiento de esta porción del litoral granadino (Figura 3). La parte inferior delinea con elevada exactitud el perfil de la franja costera orientado al $\mathrm{N} \mathrm{y}$ donde se propone la construcción de la batería adosada a la torre vigía. Siguiendo la disposición O-E, se aprecia perfectamente la alternancia del paisaje litoral que se produce entre la playa de Calahonda formada esencialmente por arenas y piedras, siendo el enclave seleccionado para la ubicación del puerto en prolongación con una sección acantilada y escarpada a resguardo de los vientos de levante. También se dispone de una interesante ornamentación, con un dibujo de la rosa de los vientos acompañado de unas líneas rectas que establecía los distintos rumbos a seguir por las embarcaciones en los casos de partida y llegada. La parte superior del plano se destina en su margen izquierda a la ubicación de la leyenda mientras que en su lado opuesto, se observa el diseño con el resultado final de la torre batería situado sobre un extremo de la superficie que coincide

12 A.G.S.G.M.: Leg. 3419, s.n.

13 A.G.S.G.M.: Leg. 3421, s.n. 
con el inicio de los acantilados. Para facilitar la comunicación entre la batería y su torre, se aprecia la necesidad de habilitar una pequeña cámara en la parte inferior de su estancia principal y mediante el empleo de una buhera con escalera, posibilitar su conexión.

Según Informe de Francisco Gozar sobre el estado de las fortificaciones de la costa del Reino de Granada de 18 de agosto de $1774^{14}$, se confirma que la Torre de Calahonda fue adaptada para dos cañones de a 8 y que quedó en estado de servicio en fin de diciembre último (posiblemente del año 1773). Y de la Relación efectuada por Joaquín de Villanova sobre los reparos necesarios en la costa del Reino de Granada y donde se incluye el suplemento de José de Veciana de los años 1783 y $1784^{15}$, se admite que para la composición de la puerta de la Torre de Cala Honda se precisan de una tabla de 4 varas y 10 clavos de entablar y un cerrojo de a tercia.

El Informe de Felipe de Paz sobre el estado de las fortificaciones de la costa del Reino de Granada de 09 de abril de $1803^{16}$, señala que la Torre de Calahonda es de fábrica antigua y que a su frente tiene más baja una batería para dos cañones de pequeño calibre. Acto seguido la sitúa a la altura de una punta de peña que avanza al mar y resalta su cometido al abrigo de la cala que se sitúa próxima y de buen fondo. Concluye destacando la necesidad de mantener la efectividad de la fortificación al encontrarse junto a un muelle que está habilitado para la saca de frutos y que convendría que se poblara con determinado buen orden.

En esta muestra cartográfica del año 1803 se observa una mejora en la evolución del diseño aunque conserva su estilo respecto a la analizada del año 1770 (Figura 4). La utilización de la gama de los colores en los trazados indudablemente favorece a realzar su embellecimiento y a potenciar la divulgación. El plano se ha dividido en tres partes, siendo la ubicada en la parte inferior izquierda la que refleja con gran detalle un fragmento de su perfil, con una zona llana y arenosa donde se encuentra perfectamente identificada la ubicación de su puerto junto a otra asociada al relieve de montaña que alcanza el mar en forma de pronunciados acantilados (tonalidad oscura). Como novedad podríamos añadir que diseña en una incipiente actividad de ordenación del territorio, lo que podría corresponder a los inicios del núcleo poblacional de Calahonda, en una clara vinculación de algunos de sus vecinos con a la actividad portuaria. En la parte superior se vuelve a incidir en la posición geoestratégica de la torre batería, no representando con tanta exhaustividad la localización extrema al inicio de los roquedos escarpados. Y finalmente, la parte derecha del plano se dedica a una amplia leyenda informativa.

Por su funcionalidad destinada principalmente a la navegación, podríamos identificar el plano del año 1813 como una carta náutica que añade una fracción de la costa, sin incluir su toponimia (Figura 5). En ella podemos apreciar el peculiar diseño de la ensenada de Calahonda y de la situación de su muelle a resguardo de las corrientes de levante. Por su simplicidad y en la búsqueda de lo práctico, resulta evidente que los destinatarios en su mayoría eran navegantes y marineros, de ahí que carezca de una ornamentación que lo adornara. Además de la información sobre la tipología de los fondos marinos y profundidad, también añade las importantes líneas rectas que como ya se ha comentado facilitaban las maniobras de aproximación y salida de las embarcaciones.

\footnotetext{
14 A.G.S.G.M.: Leg. 3424, s.n.

15 A.G.S.G.M.: Leg. 3429, s.n.

${ }^{16}$ I.H.C.M.C.G.D.: Leg. 4-5-2-5.
} 
Figura 4. Plano del puerto de Calahonda con el proyecto de ampliación a una población en sus inmediaciones, de fecha 24 de agosto de 1803

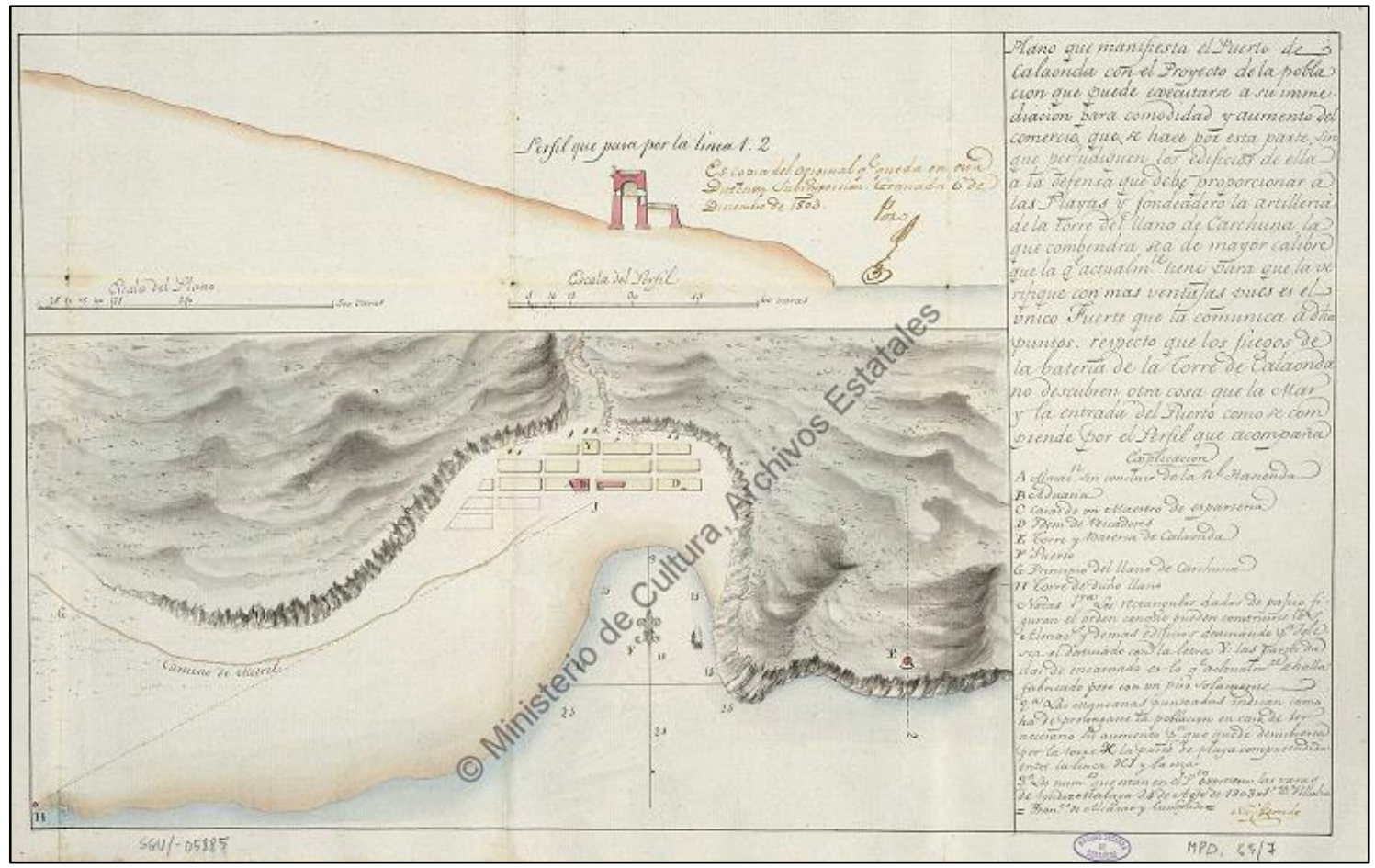

Fuente: España. Ministerio de Educación, Cultura y Deporte. Archivo General de Simancas. MDP, 65 , 007. Ubicación Anterior: SGU, 05885. http://www.mcu.es/ccbae/es/consulta/registro.cmd?id=181683

Figura 5. Plano de Calahonda del año 1813

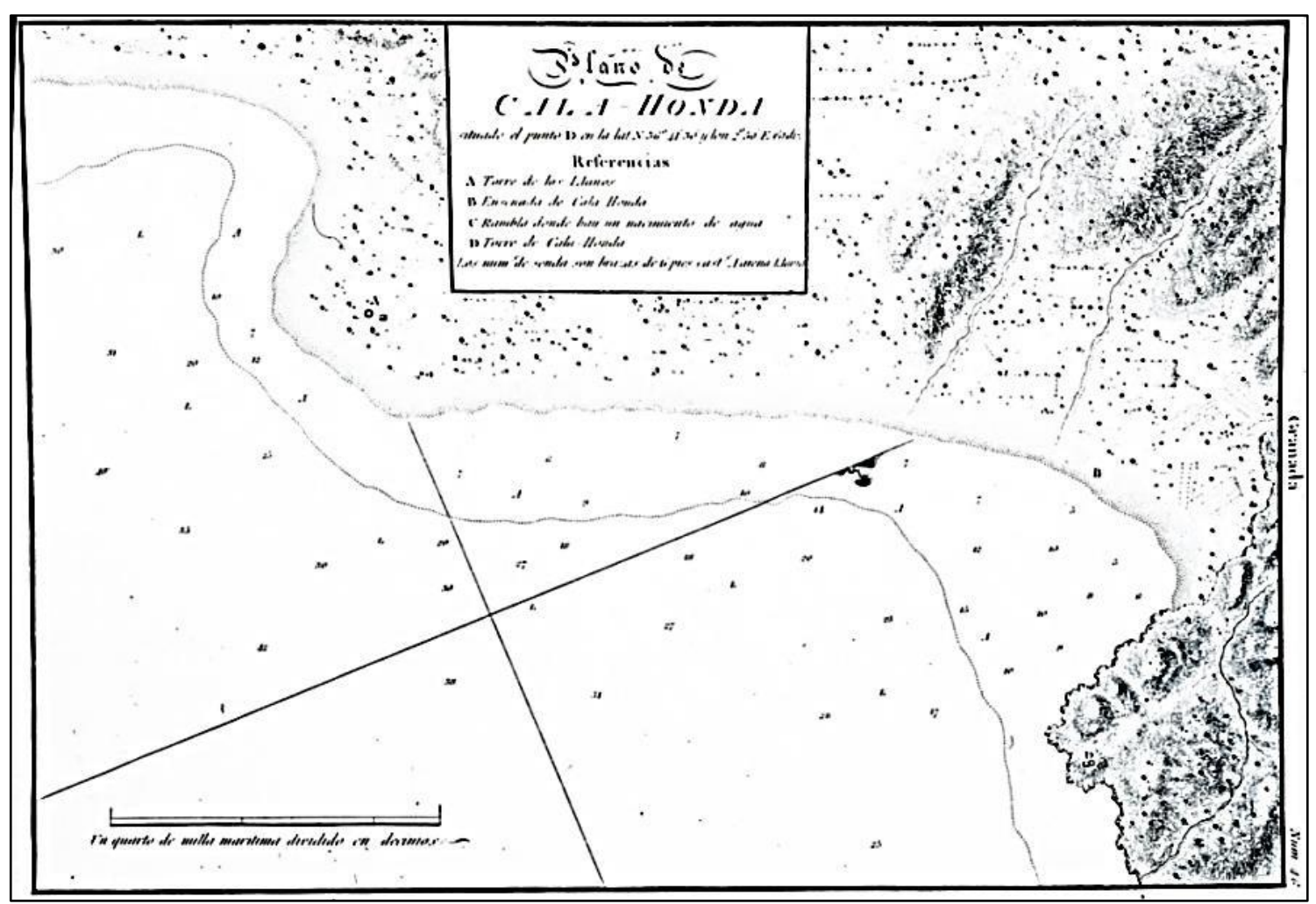

Fuente: España. Ministerio de Defensa. Archivo General Militar. http://www.portalcultura.mde.es/cultural/archivos/ 
Del Informe de Mauricio Rodríguez de Berlanga sobre el estado de las fortificaciones de la costa del Reino de Granada de 24 de marzo de $1830^{17}$, se describe la ubicación y evolución de la primitiva torre vigía a una más desarrollada con la incorporación de su batería. En su funcionalidad defensiva, la destina especialmente a la custodia de la embocadura de levante del puerto de Calahonda, además de la obligatoriedad de comunicarse con las inmediatas y de la necesidad de mantener un fuego cruzado con la batería de la fortaleza abaluartada de Carchuna. En el mismo documento se propone aumentar el número de efectivos, en esta ocasión en un artillero para una plantilla ya integrada por un cabo y tres torreros. Insiste en que la comunicación entre estas fortificaciones seguía siendo complicada, de ahí que estimara la comunicación en línea recta con la batería provisional de Calahonda en cinco cuartos de hora de camino o media legua.

Y el Informe de Miguel de Santillana sobre el estado de las fortificaciones de la costa del Reino de Granada de 10 de diciembre de $1849^{18}$, sitúa la Torre de Calahonda a unos 200 pies sobre el nivel del mar y 150 distante del mismo, con una batería adosada a su frente, susceptible de contener 2 piezas de a 24. Aunque reconoce que durante el día está desartillada, a pesar de la disponibilidad de 2 cañones en ella de hierros clavados o inútiles, su importancia geoestratégica radica en la posibilidad de realizar fuegos cruzados por el E con los del fuerte de Castell de Ferro y por el O con los de la batería rasante de Calahonda y los de la torre del Llano de Carchuna, por lo que ratifica la conveniencia de su mantenimiento, considerándola indispensable para la conservación de este puesto, ocupado por los Carabineros desde el año 1839. La incorporación del cuerpo militar de Carabineros en las labores de la protección y seguridad hizo que al NE de la fortificación y como a tiro de fusil se construyera una casa que fue ocupada por los soldados carabineros.

De la completa y última Memoria descriptiva militar sobre la topografía, defensa y observación de la costa del Reino de Granada realizada por José Herrera García de 15 de marzo de $1857^{19}$, describe la torre de Calahonda con una batería adosada en figura de corona, capaz de montar dos cañones. En la misma crónica justifica su mantenimiento, al ser una franja donde suelen venir a hacer aguada los buques enemigos y los contrabandistas aprovechan para desembarcar sus alijos con facilidad. Por lo que reclama un aumento de fuegos para este punto, reemplazando para ello la pequeña batería provisional de Calahonda con otra casamatada de segunda orden. Examina conveniente que cruce sus fuegos con los de la torre artillada de los Llanos de Carchuna, situada en el extremo occidental del mismo puerto y entendida como fortaleza fundamental al descubrir por poniente hasta la punta del Chucho que coincide con el inicio de la playa de Motril. Y hacia Levante confiesa que todo el hueco que constituye el seno de Calahonda lo necesitan los buques para entrar en él, de ahí que en palabras textuales afirme que vienen lamiendo sus arenas. Por lo que cree a esta fortificación clave en el auxilio de aquel muelle y bajo tal concepto, como construcción defensiva de especial disposición.

\footnotetext{
${ }^{17}$ I.H.C.M.C.G.D.: Leg. 4-5-2-11.

${ }^{18}$ I.H.C.M.C.G.D.: Leg. 4-5-2-14.

${ }^{19}$ I.H.C.M.C.G.D.: Leg. 5-5-12-2.
} 


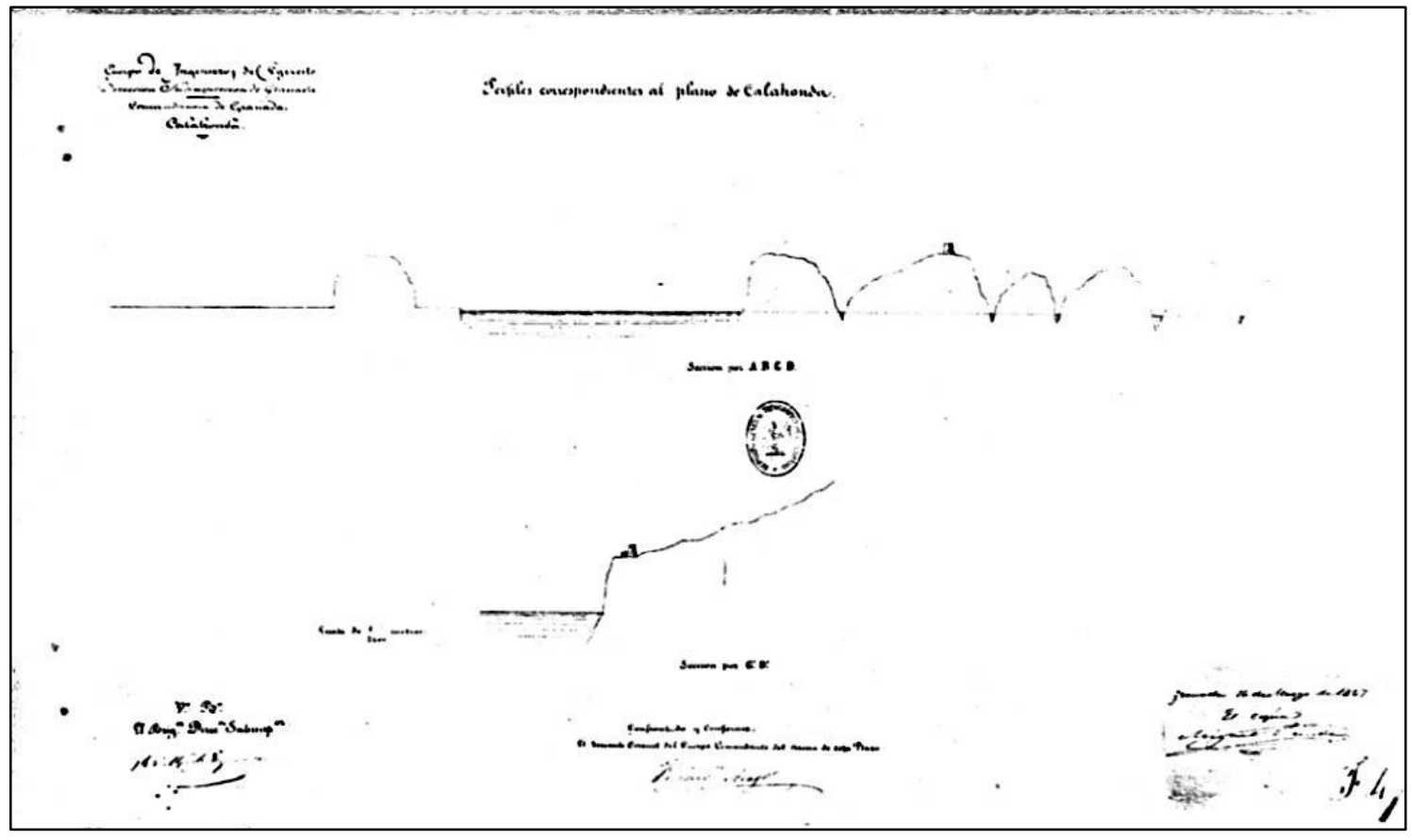

Fuente: España. Ministerio de Defensa. Archivo General Militar. http://www.portalcultura.mde.es/cultural/archivos/

En la esquemática pero significativa representación cartográfica de las proximidades de la torre del Zambullón, dividida en dos partes con sus respectivos perfiles topográficos del año 1867, la identifica en una fase acantilada, de complicado acceso por su pronunciado roquedo y acusada pendiente (Figura 6). Entretanto, en el corte topográfico de orientación $\mathrm{N}$ situado en la parte superior se localiza nuestra fortaleza de estudio en su segundo promontorio; en la parte inferior y en un perfil de disposición O-E, se observa su ubicación en el extremo que da inicio a los acantilados, resaltando en el diseño de su planta la figura de una batería que tiene adosada a su cuerpo (Figura 7).

La acumulación de planos y mapas con ausencia de detalles ornamentales nos informa que tanto los navegantes como los militares que prestaban sus servicios en la ensenada de Calahonda eran sus destinatarios primordiales. El diseño cartográfico del año 1867 recoge el desarrollo urbanístico que ya había comenzado en las cercanías de su playa, siguiendo posiblemente las indicaciones señaladas en la certificación de Felipe de Paz e identificadas en el plano del año 1803. Se produce el levantamiento de las incipientes construcciones de viviendas, vinculadas algunas de ellas a la explotación de la tierra (identificándose algunas de las parcelas destinada al cultivo) y el mar, mientras que otras fueron destinadas a las instalaciones que acogiera al personal empleado en la seguridad y a la proyección de las actividades comerciales del puerto.

Y añadir que, en cuanto al significativo estado de las comunicaciones terrestres para la organización espacial de todo este complejo sistema defensivo y social, la provincia de Granada y en su articulación hacia el eje costero, a mediados del siglo XVIII seguían resultando desastrosas, limitando de forma crucial las posibilidades de desarrollo que primordialmente desde el mar se ofrecía con otros centros de consumo y producción (Martínez, 1992). Estas deficiencias por cuestiones políticas y económicas se fueron 
arrastrando hasta alcanzar la mitad del siglo XIX cuando se ejecutó el camino que unía las localidades de Granada y Motril.

Figura 7. Proyecto de la zona o explanada de servicio en las inmediaciones de la Torre de Calahonda, del año 1867

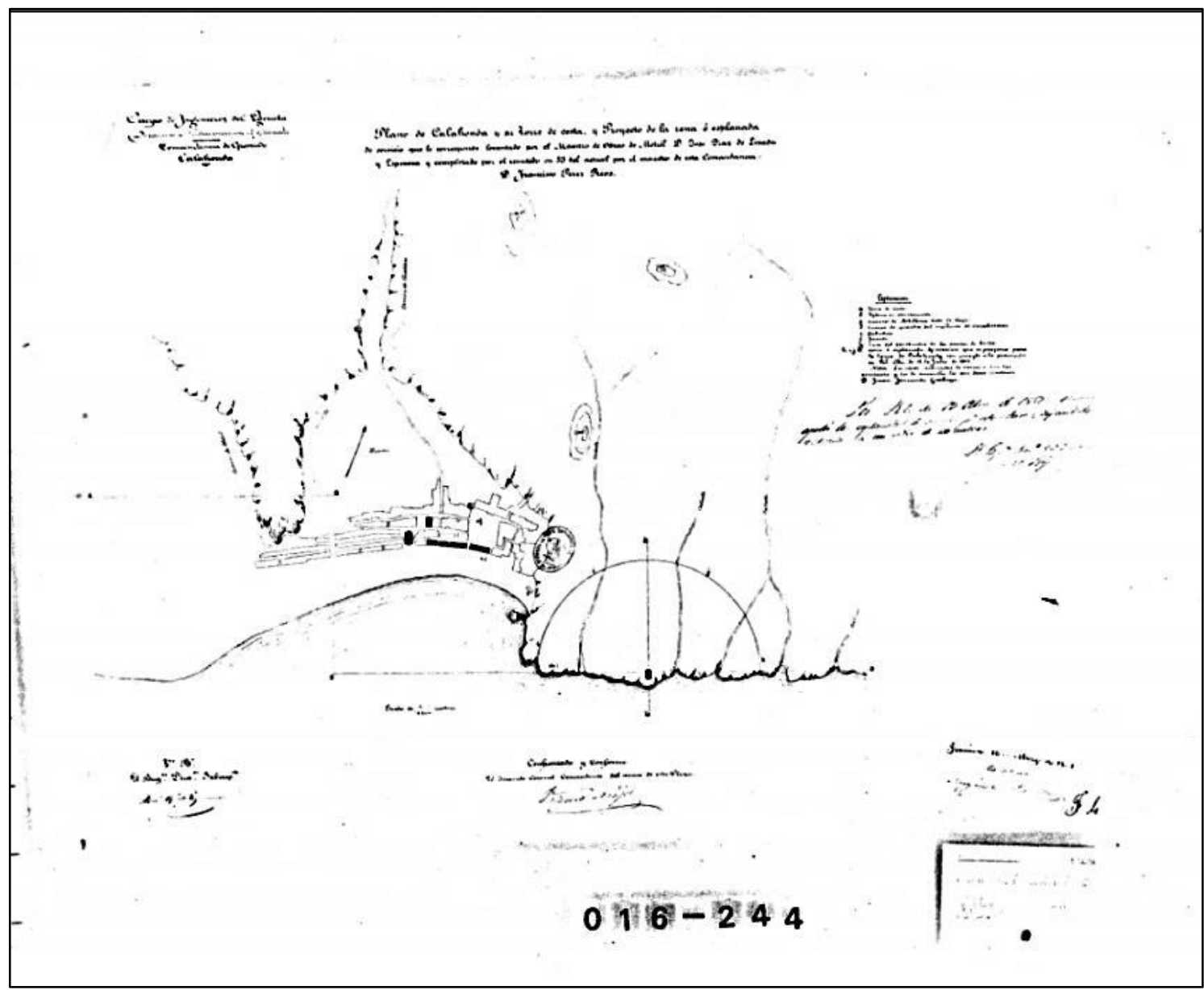

Fuente: España. Ministerio de Defensa. Archivo General Militar. http://www.portalcultura.mde.es/cultural/archivos/

Del fragmento del interesante mapa geográfico del año 1868 se aprecia como el puerto y el núcleo poblacional de Calahonda disponía en dirección $\mathrm{O}$ de dos alternativas de comunicación terrestres hasta alcanzar Motril (Figura 8). La primera de ellas y quizás la más importante era un camino carretero, conocido por el nombre de la Noria, que discurría por su parte interior y que enlazaba con otros caminos de herradura que articulaban las poblaciones situadas en altura de la sierra de Lújar. La segunda opción de paso era haciendo uso de un camino de herradura próximo al mar que atravesaba mediante un trazado rectilíneo el Llano de Carchuna, para bordear el cabo de Sacratif por la parte posterior de la torre del Chucho y tras acceder al caserío de la salina de Torrenueva, continuar hasta Motril. Sin embargo, hacia el E todavía se carecía de una comunicación comercial directa por la costa hasta el siguiente núcleo poblacional, debiendo de realizarse mediante un camino de similares características al anterior pero en esta ocasión, con un trayecto por el interior hasta alcanzar la población de Gualchos y a continuación, hasta el núcleo de Castell de Ferro. 
Figura 8. Plano General de la costa con la situación de las diferentes torres vigías, artilladas, reductos y castillos que existen en la misma del año 1868

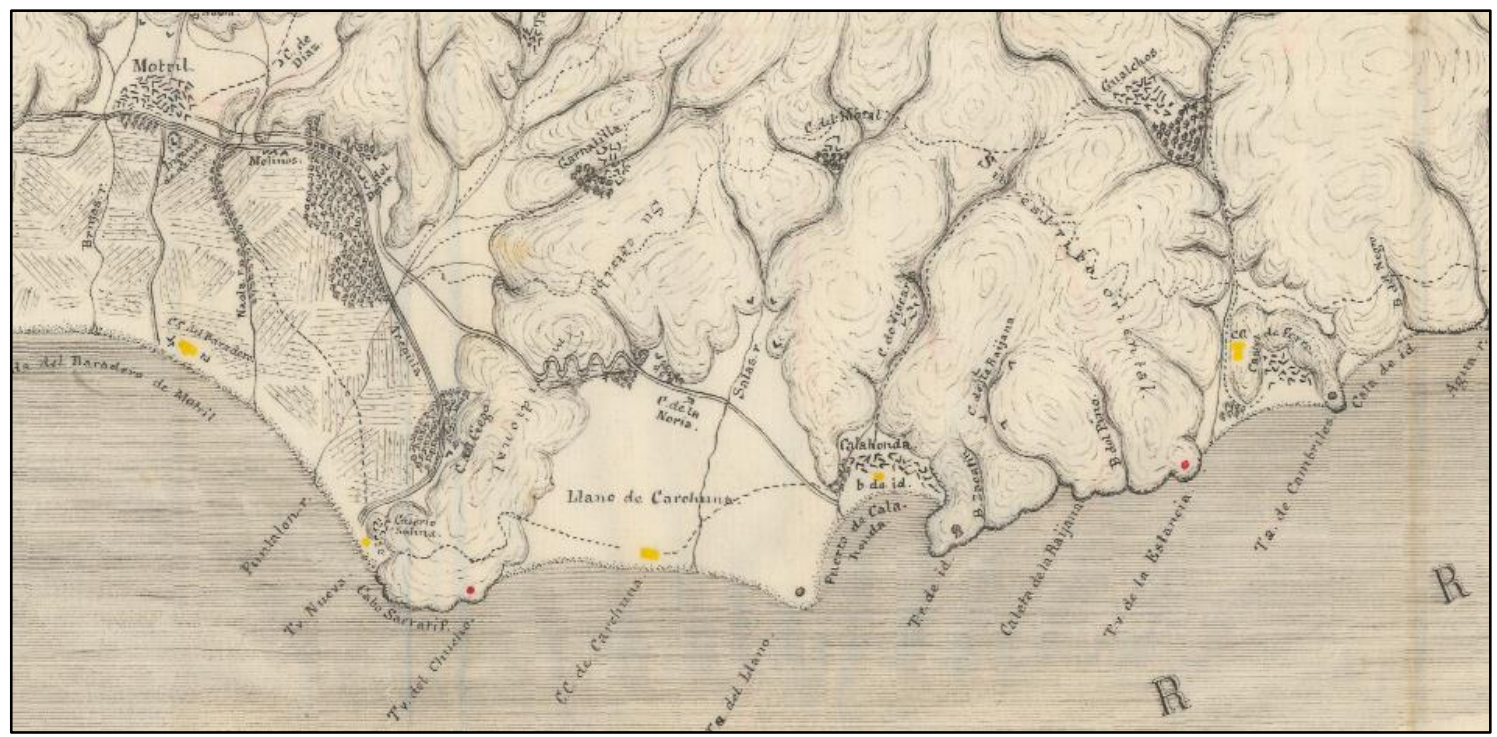

Fuente: España. Ministerio de Defensa. Archivo General Militar. http://www.portalcultura.mde.es/cultural/archivos/

A lo largo de la segunda mitad del siglo XIX y con el inicio de la incipiente actividad ferroviaria a escala peninsular que se planteaba como una posible solución a los males comunicacionales que se mantenían, motivaron que se presentaran diferentes proyectos de articulación desde la ciudad de Granada siempre en la búsqueda de los intercambios comerciales a través del mar, siendo preferente las propuestas de conexión con la ciudad de Málaga. La iniciativa original en la cimentación de la línea de Granada al muelle de Calahonda data del año 1855, cuando se solicitó autorización expresa de estudio y antes de concluir ese siglo, le siguieron otras que igualmente fueron rechazadas o abandonas en sus trámites preliminares (Martínez, 1992).

A partir del año 1883, el puerto de Calahonda que por entonces era el único habilitado para el traslado de la mensajería marítima y el transporte de personas y mercancías de la provincia de Granada (Posadas, 1996) cesó en su uso, dando paso al inicio de la actividad portuaria en unas nuevas instalaciones, en una zona relativamente próxima y conocida como Varadero, perteneciente también al municipio de Motril. Desde entonces, el sentido defensivo que comprendía el mantenimiento y la operatividad de todas estas fortalezas más inmediatas al muelle de Calahonda perdieron importancia y con ello, el inicio de un proceso progresivo de decadencia.

De la representación cartográfica del año 1933 se puede apreciar como la comunicación terrestre en dirección E ya era una realidad, con una carretera que comunicaba las provincias de Málaga y Almería y que a su paso por nuestro ámbito de estudio se convirtió en un trazado serpenteante asociado al perfil abrupto del relieve de las ultimas estribaciones de la sierra de Lújar que alcanzan el mar (Figura 9). En cuanto a la situación de la torre del Zambullón posiblemente todavía conservaba su batería anexa, ya que el diseño de la vía lo hacía por su parte posterior, lo que pudo suponer que no se convirtiera en un obstáculo para la continuidad de la carretera. 
Figura 9. Mapa del término municipal de Gualchos del año 1933

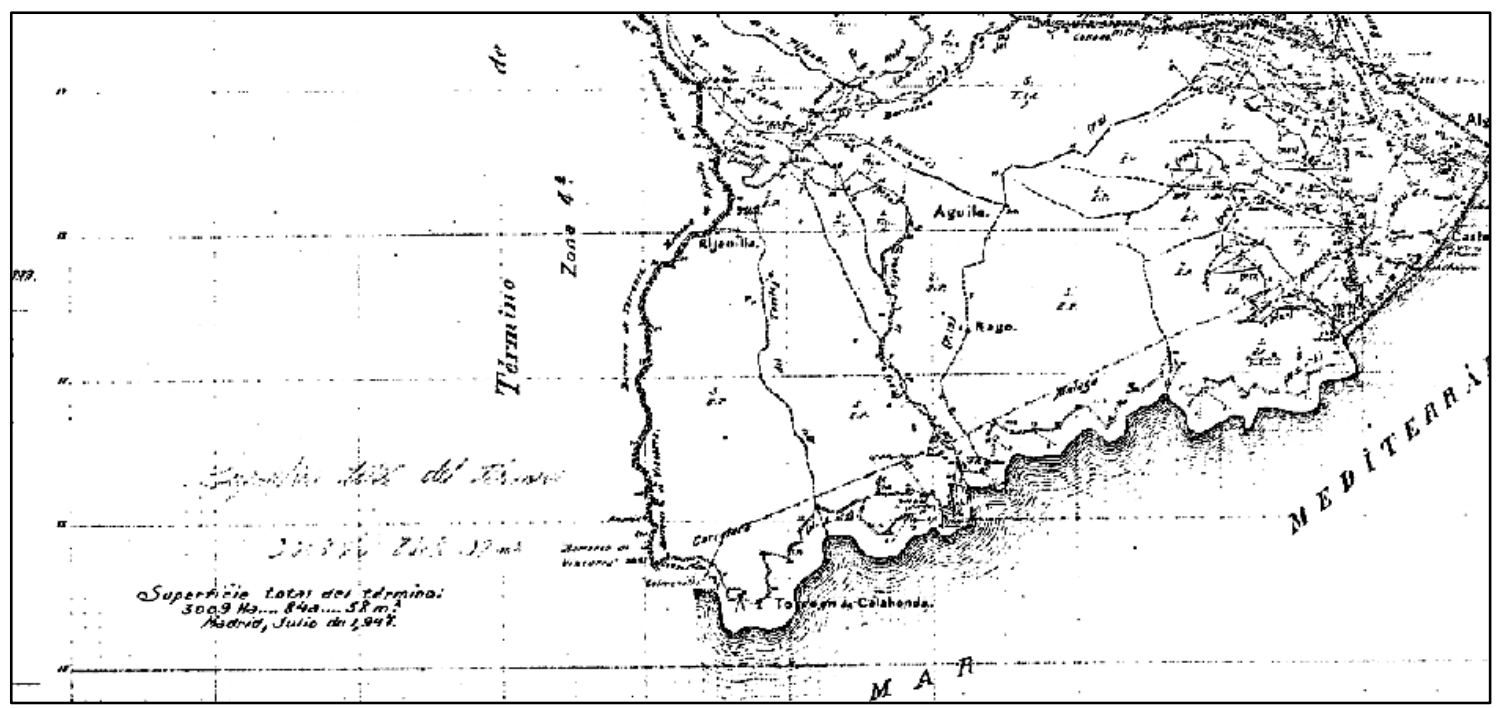

Fuente: España. Ministerio de Transportes, Movilidad y Agenda Urbana. Instituto Geográfico Nacional AD IECA1989003814.

La primera imagen disponible resultó del vuelo americano de los años 1945-1946 donde podemos apreciar que por la futura democratización del vehículo, se hizo necesario la circunvalación de la carretera a la altura de la torre, mediante la abertura de un nuevo trazado que incluyera su ampliación y pavimentación que evidentemente por el espacio necesario llevó aparejado la eliminación de la batería que por entonces mantenía anexada a su cuerpo. Añadir también que, el núcleo poblacional de Calahonda que como hemos tenido ocasión de comprobar se originó en sintonía a las actividades económicas y comerciales de su puerto y a pesar de su abandono posterior, se mantuvo con trabajadores y sus familias en una economía de subsistencia, básicamente vinculadas a los recursos provenientes de la explotación agraria y pesquera (Figura 10).

Figura 10. Núcleo poblacional y torre de Calahonda, captada del vuelo americano Serie A, años 1945-1946

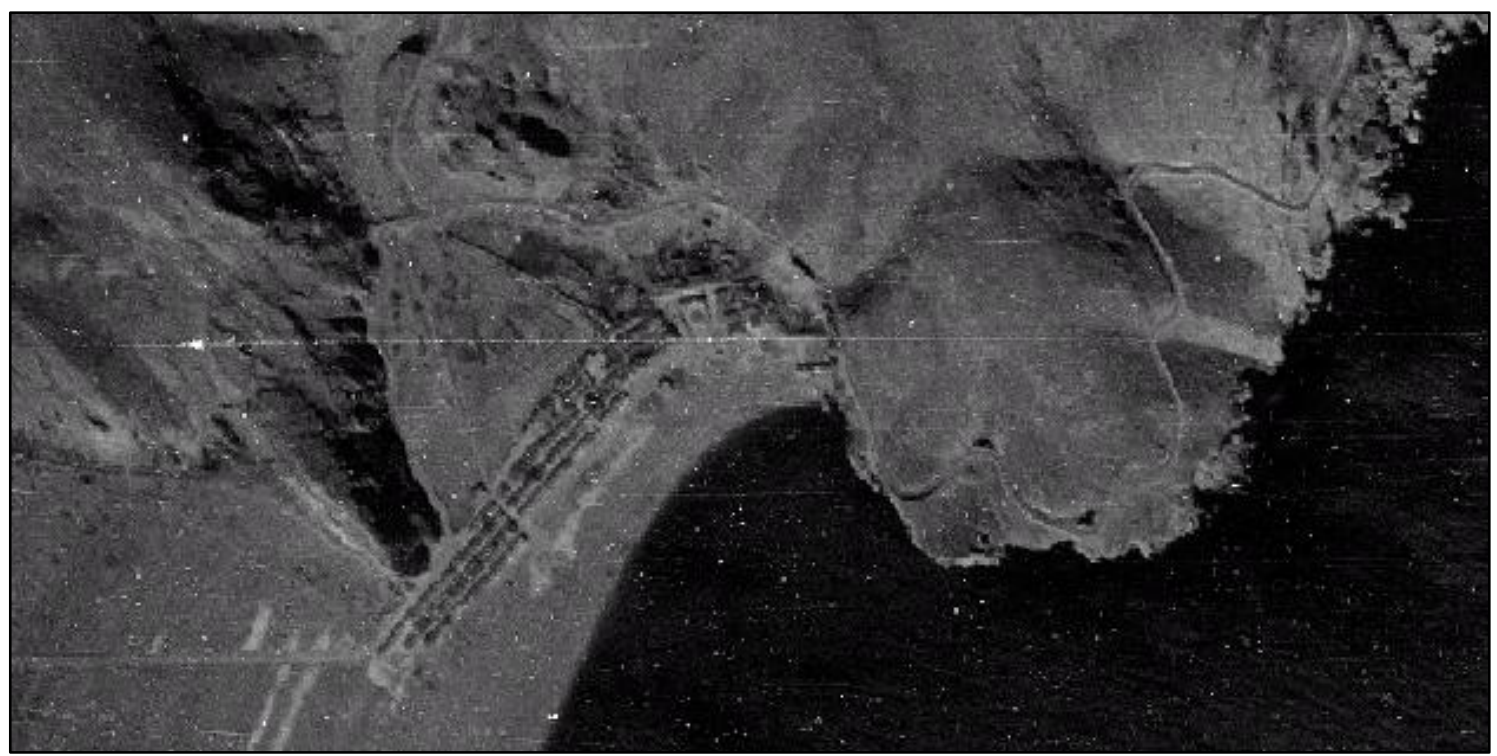

Fuente: España. Ministerio de Transportes, Movilidad y Agenda Urbana. Instituto Geográfico Nacional. 


\section{ANÁLISIS CARTOGRÁFICO Y DOCUMENTAL}

Con mayor incidencia a partir del siglo XVI, los acantilados próximos a la playa de Calahonda que sirvieron a su embarcadero y posterior muelle al resguardo de los vientos de levante, se dedujo por su disposición en el refugio costero del Reino de Granada como un emplazamiento estratégico de especial vigilancia que garantizaba la organización de la justicia y de la recaudación fiscal. Así quedó recogido en el asesoramiento que elaboraron de su visita Antonio de Berrío y Luís Machuca durante el año 1571, señalando que la estancia de la Cala del Harena se encontraba desierta, si bien, solía tener dos guardas y que se recomendaba construir una torre en la punta de la cala que podría ofrecer inmunidad a un ámbito frecuentado por enemigos. Hecho que se vuelve a recomendar mediante carta de fecha 29 de diciembre de 1575, ampliándose con ello la firmeza hacia Cala Onda.

Después de un vacío documental donde destacan diversos libramientos económicos destinados a la edificación y mejora de la fortaleza de Calahonda, se alcanzó el año 1726 cuando Bartolomé Amphoux elaboró un dossier sobre el estado de las fortificaciones de la costa del Reino de Granada y resaltó el buen estado que presentaban las seis torres que se situaban entre los castillos de Salobreña y Castell de Ferro, siendo una de ellas nuestro edificio de estudio. Del anuncio elaborado por Antonio María Bucarelli y Ursúa sobre el estado de las fortificaciones de los Reinos de Granada y de Murcia hasta Cartagena del año 1762, se recogió de forma inédita la posibilidad de incorporar artillería al descubierto con dos cañones de a ocho.

Y tras los documentos de Esteban Aymerick y José Crame de los años 1765 y 1767 respectivamente, donde se proponían posibles soluciones que permitieran dotar de una plataforma a la fortificación que pudiera introducir artillería a barbeta en explanada, se alcanzó el año 1774 cuando Francisco Gozar confirmó que la fortaleza de Calahonda fue adaptada para dos cañones de a 8 y que quedó en estado de servicio a finales de diciembre último (posiblemente del año 1773).

Debemos tener en cuenta que nos encontramos en la fase inicial de aplicación del Reglamento que su Majestad Carlos III mandó observar en las diferentes clases destinadas al real servicio de la costa del Reino de Granada (18 de agosto de 1764) y ya se encontraba construido el importante recinto abaluartado de Carchuna (1769) que garantizaba por su número de efectivos la seguridad por tierra; por lo que la adaptación de la batería a la torre del Zambullón posibilitaba un interesante fuego cruzado con esta en el auxilio por mar del puerto de Calahonda, repeliendo a los buques enemigos cualquier intento de aproximación y otorgando a la retaguardia el tiempo suficiente para el despliegue de las fuerzas territoriales.

En cuanto a la cartografía y teniendo en cuenta que la técnica en la elaboración de los mapas a escala local ya se dominaban desde las civilizaciones antiguas, el plano analizado del año 1770 destaca por su rigurosa exactitud, divulgando con notable acierto el conocimiento recogido en los partes militares de los últimos años. Así, junto al interesante diseño de esta franja marítima y en ocasiones a través de una preparada ornamentación que incluía una rosa de los vientos, se informaba a los navegantes sobre los rumbos de aproximación y salida del muelle. También se identificaba con gran fiabilidad el emplazamiento destinado a la torre batería. Debemos tener en cuenta que estas cartas náuticas solían contener información confidencial de elevada precisión que indudablemente anhelaban los tripulantes de los buques enemigos, llegando a convertirse en ocasiones el objeto más preciado en los botines de los barcos capturados. 
A pesar de las dificultades económicas que caracterizaron el final del siglo XVIII e inicios del XIX y que posteriormente arrastraron a la guerra de la Independencia, Felipe de Paz en el año 1803 elaboró otro testimonio sobre el estado de las fortificaciones donde realizó una cuidadosa descripción de la localización de la torre de Calahonda y donde se planteó de forma ingeniosa junto al sustancioso plano de ese mismo año, potenciar las actividades comerciales del puerto que custodiaba, afirmando que estaba habilitado para la saca de frutos y como novedad destacable, en una incipiente ordenación del territorio para la época, se propuso la conveniencia de posibilitar el poblamiento de su entorno más inmediato que a su parecer favorecería con el buen orden a las propias tareas del muelle.

De las diferentes relaciones militares que se sucedieron a lo largo del siglo XIX, podemos destacar las limitaciones de tipo armamentístico que se iban recogiendo, derivadas de la falta de mantenimiento y adecuación de la artillería al descubierto que portaba y que comprometía la funcionalidad de la torre de Calahonda. A pesar de esos inconvenientes, a raíz de la crónica de Miguel de Santillana del año 1849 se constató la ocupación y utilización de la fortaleza por el Cuerpo de Carabineros desde el año 1839, en sus funciones de vigilancia de costas y fronteras y la represión del fraude fiscal y del contrabando.

De la última memoria descriptiva militar disponible y elaborada por José Herrera García en el año 1857, se pudo constatar que la construcción de Calahonda seguía manteniendo adosada a su cuerpo una batería, en forma de corona y con capacidad para montar dos cañones de a 24 (hecho que demuestra la efectividad de la fortificación que desde el año 1774 se adaptó a dos cañones de a 8 y décadas más tarde se entendía que podía albergar artillería de gran calibre). La eficacia de este elemento defensivo se pudo corroborar mediante los planos del año 1867 que seguía recogiendo la torre y su batería en una misma pieza; y del año 1868, donde se carecía del camino litoral de comunicación terrestre en dirección E hasta el siguiente núcleo poblacional de Castell de Ferro, debiendo de realizarse previamente por el interior hasta la población de Gualchos. Igualmente de estas fechas se pudo comprobar como el inicio urbanístico había comenzado en las inmediaciones de su playa, con el levantamiento de las construcciones de viviendas y almacenes para las personas vinculadas a la explotación de la tierra y el mar junto a las actividades comerciales del puerto.

Finalmente, el mapa del año 1933 identificó el diseño de la carretera que servía de enlace a las provincias de Málaga y Almería (división administrativa desde la reforma territorial del año 1833, mediante Circular del Secretario de Estado de Fomento Javier de Burgos), mediante su trazado costero por la provincia de Granada y a la altura de la torre del Zambullón, al parecer lo hizo por su parte posterior; por lo que, se deduce que la batería se encontraba todavía anexada a su cuerpo. Sin embargo, de la clarificadora imagen proporcionada por el vuelo americano de la Serie A de los años 1945-1946, se desprendió que, años más tarde, se hizo necesaria una alternativa en su dibujo a la altura de nuestra fortaleza de estudio y que posiblemente al resultar un obstáculo para su continuidad, llevó aparejada la pérdida de su batería. Debemos tener en cuenta que la preliminar normativa proteccionista del patrimonio español se produjo mediante Decreto de 22 de abril de 1949 y siguiendo la descripción de su preámbulo, desgraciadamente todos estos vestigios del pasado estaban sujetos a un proceso continuo de descomposición sin ningún tipo de interés social ni cultural. 


\section{ESTADO GENERAL DE CONSERVACIÓN}

La torre del Zambullón se caracteriza por su figura cilíndrica, con cierta tendencia troncocónica, donde el mayor diámetro de su base le proporciona una decisiva estabilidad y robustez a diferencia de épocas anteriores para esta tipología de arquitectura defensiva. El grosor de sus muros buscaba reducir los efectos de los posibles impactos que pudieran recibir desde las embarcaciones enemigas que se aproximaban en exceso; si bien, los materiales empleados para su cimentación que se basan principalmente mediante el uso de mampostería de piedra caliza, mortero de cal y arena, en un ajuste a los desembolsos $\mathrm{y}$ presupuestos disponibles, se caracterizaban por resultar un material blando $\mathrm{y}$ relativamente deformable según la potencia del fuego atacante.

Asentada sobre un tambor tubular, se eleva en una sola pieza una estructura uniforme que culmina con una terraza ya parcialmente deteriorada por la erosión producida por los agentes atmosféricos junto a un drenaje poco eficiente que ocasionó la filtración del agua retenida. Su interior se organizaba en una cámara o estancia desde donde se proyectaba una posible escalera o cuerda interior que permitía la comunicación con la azotea. Igualmente ha desaparecido la típica ladronera que facilitaba a sus torreros garantizar el apoyo a su exclusiva puerta-ventana (orientada en dirección NE) en aquellos casos de asedios y posibles intentos de derribo (Figura 11).

Figura 11. Fachada orientada al SE de la torre del Zambullón. En la parte superior derecha se conserva los restos de su primitiva puerta ventana. A continuación, en la parte inferior se distingue el tambor tubular que da inicio a la estructura, destacando el brazo orientado al E que permitía la sujeción de la batería a su cuerpo

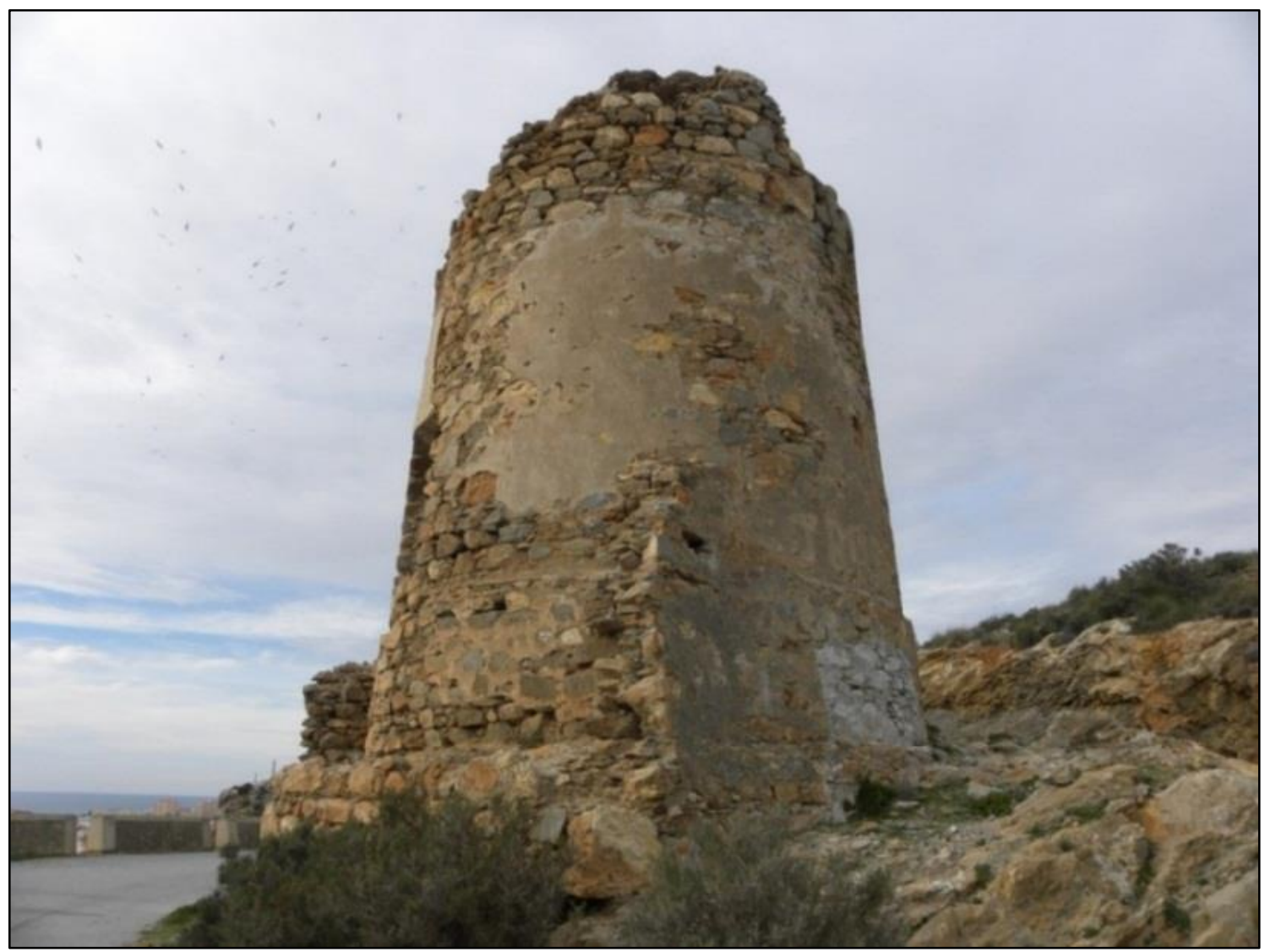

Fuente: José Ramón Sánchez Holgado, imagen captada el día 26 de enero de 2017. 
Durante la segunda mitad del siglo XVIII, la torre del Zambullón experimentó unas modificaciones estructurales que la diferenciaron de forma admirable respecto a otras empleadas a la misma finalidad defensiva y que posibilitaron desde el año 1773 la adhesión de una plataforma habilitada a la artillería a barbeta en explanada, con la inclusión de dos cañones de a ocho. Para ello se hizo indispensable la apertura de una pequeña cámara en la parte inferior de su estancia que permitiera el almacenaje de las piezas utilizadas como proyectiles y mediante el uso de una buhera con escalera (orientada en dirección $\mathrm{S}$ ), una rápida comunicación de los torreros y artilleros desde el interior de la misma con la parte superior y exterior de la batería junto a un relativo próximo y cómodo traslado de la pesada munición hasta la ubicación de los cañones.

Figura 12. Frente orientado al S de la torre del Zambullón. El orificio modificado que se conserva en su fachada corresponde con la original buhera que posibilitaba el acceso a la explanada de la batería. Los restos de los brazos que se mantienen fijos al paramento se orientan en diagonal a la proyección de la planta de la torre

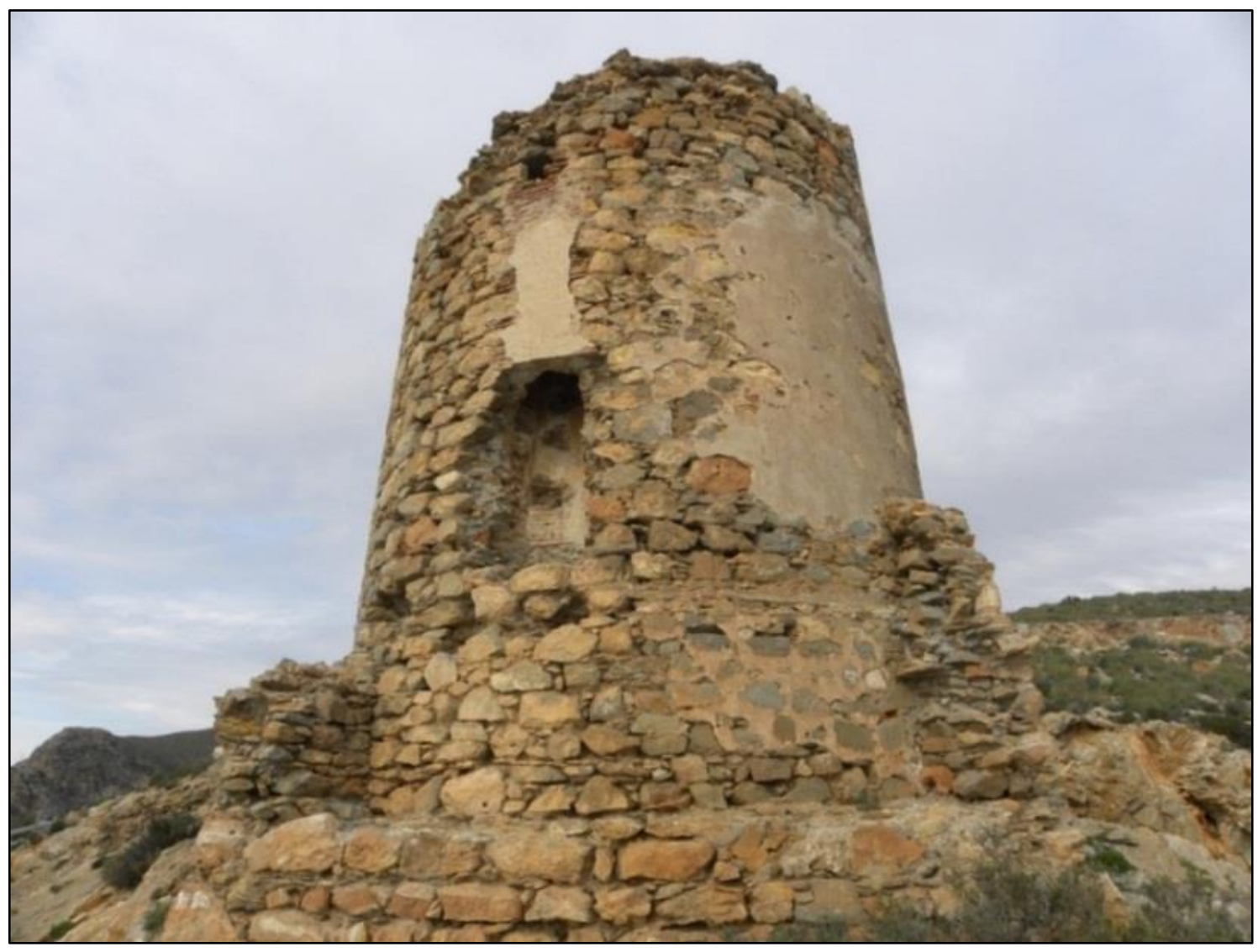

Fuente: José Ramón Sánchez Holgado, imagen captada el día 26 de enero de 2017.

En la actualidad, la fortificación se encuentra en una fase bastante avanzada de deterioro donde a las comentadas pérdidas de elementos estructurales fundamentales, hay que añadir la casi totalidad de su imponente batería que la diferenciaba respecto a las de su entorno, quedando exclusivamente los restos del paramento que le servían de fijación a los laterales de su base; pudiéndose pensar el último siglo como el periodo de mayor degradación. Desde su abandono como enclave militar no se tienen referencias de obras llevadas a cabo; por lo que el orificio que presenta en su pared, este podría corresponder en parte a la buhera que conectaba con la batería que se ha visto sustancialmente alterada 
para otros fines posteriores, ya que debido a su tamaño comunica directamente con la estancia principal, hecho que resultaba imposible debido a las diferencias de alturas existentes entre las estancias interiores y a los intereses operacionales para el correcto funcionamiento de la torre batería (Figura 12).

\section{PROPUESTAS GENERALES DE INTERVENCIÓN Y CONCLUSIONES}

Una vez alcanzado este apartado, podemos afirmar que los antiguos responsables en el diseño y de la permanencia del sistema defensivo del Reino de Granada, seleccionaron a la torre del Zambullón por su localización y sentido en la custodia de esta franja costera y especialmente del puerto de Calahonda. Y valorando sus criterios técnicos de construcción y estado de conservación estimaron que resultaba apta por métodos operacionales para su mejora, readaptándola para la importante incorporación de la artillería a barbeta en explanada; convirtiéndose en un corto espacio de tiempo en uno de los posibles escasos ejemplos donde se pudo llevar a cabo la transformación de la originaria torre vigía en una ampliada torre con batería para dos cañones.

Del presente estudio de investigación se tiene la convicción de que con una inmediata recuperación que no se caracterizaría por su complejidad jurídica, al quedar la fortificación actualmente aislada en un saliente de los acantilados, carente de uso social (al haberse abandonado el tramo de la antigua carretera que la circundaba) ni posiblemente de tipo económico por el gasto relativamente discreto que supondría las tareas de restauración, se podría disfrutar de un ejemplo de arquitectura militar único en la costa granadina (Posadas, 1996).

Con el objetivo de atenuar aquellos gastos que pudieran resultar descompensados para unas administraciones locales y provinciales ya limitadas económicamente, destacar la interesante colaboración prestada a través de los programas de las escuelas taller y casas de oficios, posteriormente conocidas como talleres de empleo. Con el desarrollo de estos planes se le ofrecía a un sector de la población vinculado al municipio la posibilidad de integración en el mercado laboral a través de la formación ocupacional, lo que suponía además por su cercanía una relación especial con el proyecto de intervención, con un ejemplo en esta comarca donde se alcanzaron unos resultados más que aceptables, como fue el caso de la recuperación del castillo de los Ulloa (Vélez de Benaudalla, año 2002).

La existencia de otros modelos recientes en actuaciones sobre el patrimonio defensivo en esta comarca, como las llevadas a cabo durante el año 2011 con la restauración de la fortaleza de Carchuna (Motril), adaptándose a una nueva funcionalidad orientada hacia las energías renovables como centro de capacitación y más modernamente, la torre de Torrenueva (Torrenueva Costa) junto al acondicionamiento de sus alrededores como parque de uso infantil, animan a asentar las posibilidades del presente proyecto de investigación.

Con la recuperación de la torre del Zambullón se dispondría de un elemento museográfico referente de la arquitectura defensiva, que perfectamente se podría integrar con otras ofertas turísticas de la misma temática como el centro de interpretación de la cultura de la Costa Tropical en Gualchos-Castell de Ferro y de la visita de las restantes fortificaciones, que solo para nuestro ámbito de estudio de carácter municipal se podría completar siguiendo en dirección O-E, con la torre de La Rijana (cronología medieval), la atalaya de La Estancia (siglo XVIII), el castillo de Castell de Ferro (cronología medieval) y la atalaya de Cambriles (siglo XVI). 
Se considera que con una apropiada refuncionalización de la fortaleza del Zambullón se facilitaría el acceso a su interior, donde se podría mostrar a los visitantes su estructura, piezas de seguridad y las condiciones de estancia de sus antiguos torreros. Para proseguir a través de su antigua batería reconstruida, lo que permitiría por la altura alcanzada próxima a los acantilados realizar una mejor comprensión de su importancia geoestratégica y funcional, resaltando la riqueza en la visión de su reconocido entorno medioambiental y paisajístico.

Dentro de la capacidad que acumula el patrimonio natural y cultural como recurso para favorecer el desarrollo territorial (Ballart y Jordi, 2001), asentado desde hace años mediante el empleo de los fondos y programas culturales comunitarios destinados a la actuación a escala local, con la restauración y puesta en valor de la torre del Zambullón, independientemente del uso que se le fuera a dar al edificio, se podría readaptar el contorno del bien interés cultural, también carente de funcionalidad, imprimiendo en su conjunto carácter al territorio (Barceló de Torres et al., 2014).

Con una ordenación adecuada, no solo se facilitaría la accesibilidad a la visita pública sino que mediante la creación de un área multidisciplinar, se podría potenciar la comprensión y promoción de estos bienes culturales y medioambientales (adecuar las comunicaciones, saneamiento y acondicionamiento del sitio, incorporación de paneles informativos en puntos singulares...) y donde se lograría afianzar la conciencia social e incentivar su conocimiento (Ruíz, 2004); de tal forma que, más lo valoraremos y mejor lo conoceremos, si apreciamos y potenciamos su reconocimiento (Cobos, 2014) (Figura $13)$.

Figura 13. Imagen tomada desde la terraza de la torre batería del Zambullón y donde se aprecia la superficie disponible en sus inmediaciones, que oscila en torno a los $2.000 \mathrm{~m}^{2}$

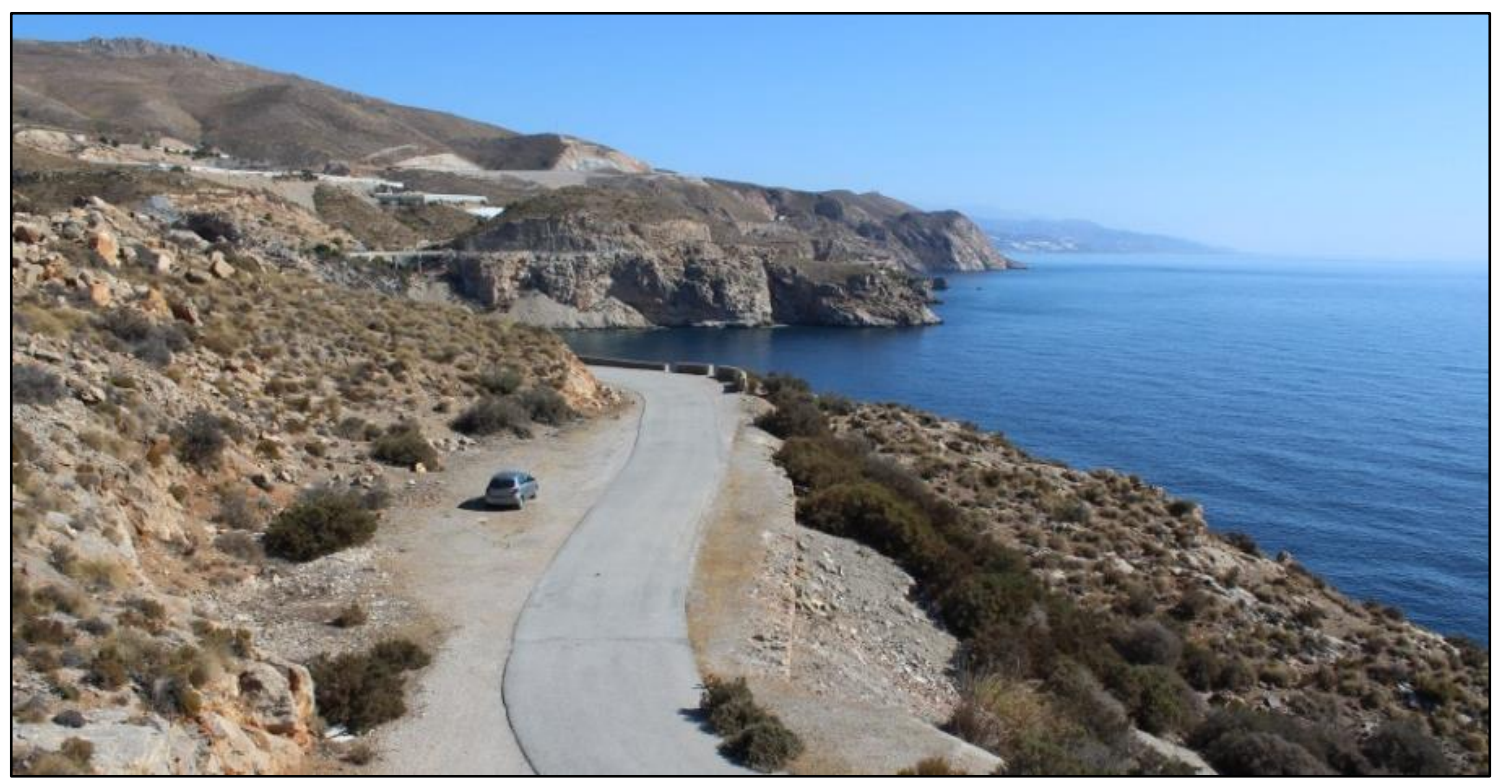

Fuente: José Ramón Sánchez Holgado, imagen captada el día 09 de octubre de 2019.

Con una gestión apropiada acorde a los criterios de sostenibilidad (Velasco, 2009) y dando cumplimiento a las recomendaciones recogidas en la Carta para la Conservación de la Arquitectura Defensiva (2006), se conseguiría ante todo recuperar un bien de interés cultural que hasta entonces y motivado a priori por su prolongado estado de abandono 
institucional y académico (Rubiella, 2014; García-Consuegra, 2017), resulta poco o nada representativo para la sociedad de la que forma parte; pudiendo a continuación poder transmitirlo a las futuras generaciones en las mejores condiciones posibles y con el reconocimiento que nunca debieron de perder (Sánchez, 2018), reforzando con ello los sentimientos de identidad colectiva y de solidaridad entre las personas (Ruíz, 2004; Fernández, 2006; Zárate, 2018).

El patrimonio está vinculado al espacio geográfico (Gómez, Sancho y Bosque, 2018) y en particular, la arquitectura defensiva (Plan de Arquitectura Defensiva de Andalucía) por lo que la recuperación de la torre del Zambullón contribuiría a imprimir carácter al territorio y con ello a la creación de paisaje (Mata, 2008). Nos encontramos en una comarca donde la historia fluye por cada rincón y sus vestigios (fortalezas y yacimientos arqueológicos) diseminados de forma estratégica resulta el mejor exponente para conformar su paisaje educativo de carácter militar (Sánchez, 2018). Ya quedó recogido en otros estudios para la misma circunscripción, diferentes actuaciones que podrían realzar la imagen del paisaje, destacando entre ellas el diseño de rutas culturales, también conocidas como históricas o turísticas-culturales (Morère, 2012), por las proximidades de estos bienes de interés cultural y la posible puesta en valor de la torre del Zambullón mediante su restauración ratifica la conveniencia de estas propuestas (Sánchez, 2015), contribuyendo a su atención, conservación, memoria e interpretación (Carta de ICOFORT sobre fortificaciones y patrimonio, 2018) (Figura 14).

Figura 14. Durante años la torre del Zambullón quedó aislada debido al necesario desarrollo de las comunicaciones terrestres y a la anchura que se hizo imprescindible para la ampliación del trazado de la carretera N-340, que sirvió posteriormente de enlace al eje comercial del Mediterráneo

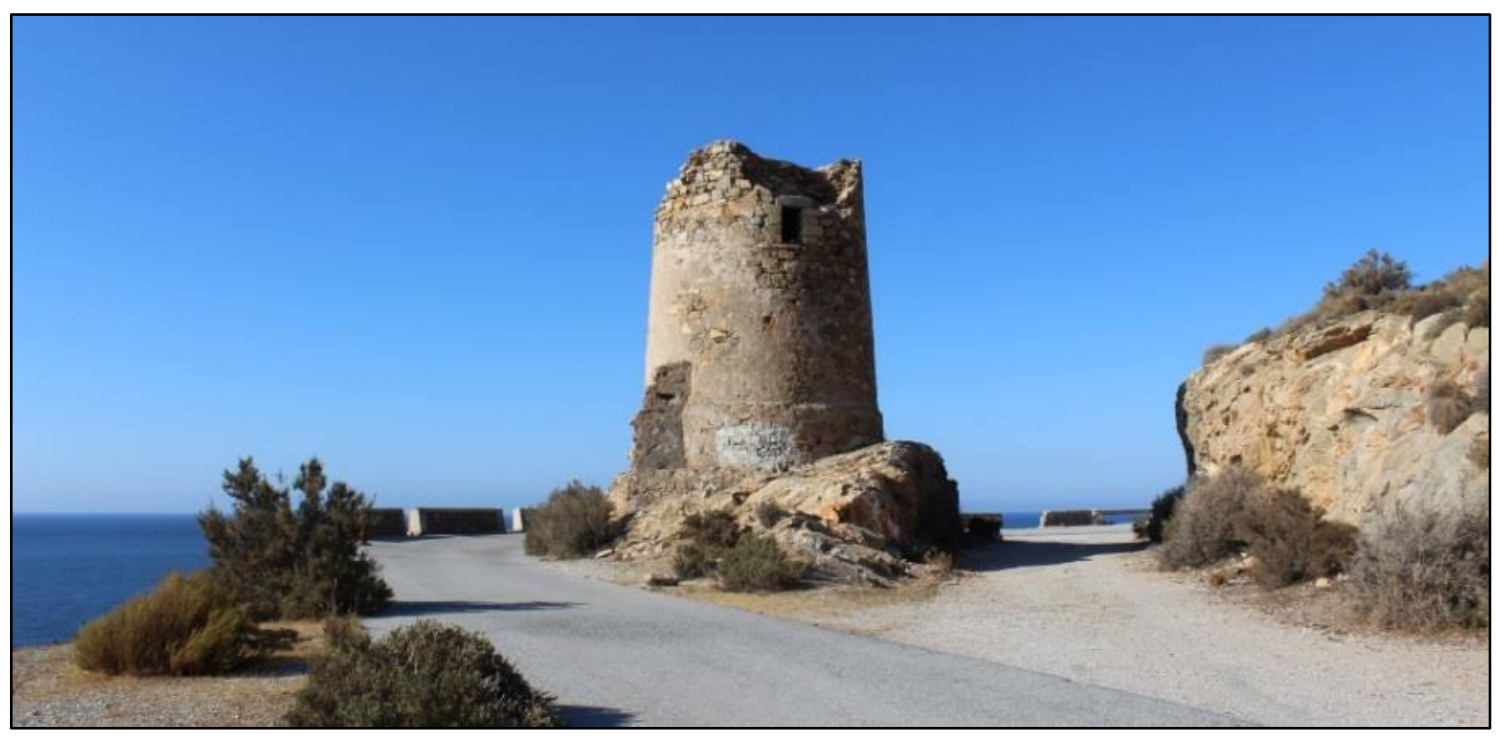

Fuente: José Ramón Sánchez Holgado, imagen captada el día 08 de octubre de 2019.

De igual forma, con una intervención adecuada facilitaría su inclusión en el mencionado inventario de recursos visitables o recomendables, en su especialidad defensiva. Nos encontramos con un ejemplo de arquitectura militar exclusiva que con la proyección o difusión a través de los diferentes canales de comunicaciones sociales aumentaría de forma destacable su atracción popular y cultural, favoreciendo el arraigo a la identidad territorial principalmente de la población local, contribuyendo con el fomento de las actividades de planificación y programación en la preservación del medio natural y, de 
carácter turístico para la atractiva demanda existente en productos culturales y de aproximación a la naturaleza (Silva y Fernández, 2008). Debemos tener en cuenta que la implicación de la población residente es la principal iniciativa para el amparo y conservación de este legado defensivo más inmediato, evitando de esta manera errores pasados donde no se tenía en cuenta ni la capacidad del territorio ni el respeto a la cultura o tradiciones locales (Baena, 2001).

Con una oportuna promoción divulgativa en la que se debería de incluir las últimas tecnologías de la información, además de favorecer a la conservación y un uso adecuado de la torre del Zambullón acorde a las exigencias sociales contemporáneas, podría garantizar su pervivencia y renovar o acrecentar el afecto en el entendimiento de este complejo sistema defensivo, del que se conservan numerosos ejemplos de diferentes cronologías y tipologías diseminadas, que contribuirían mediante la diversificación de la oferta en aumentar los beneficios económicos y sociales, rentabilizando a su vez las inversiones realizadas.

Se viene observando y así ya ha quedado recogido en algún otro estudio anterior como algunas de las corporaciones municipales gestoras de esta herencia cultural defensiva siguen interpretándolas como fortalezas aisladas y datándolas erróneamente, ajenas al importante cometido de estar integradas todas ellas de forma inseparable en la primera línea defensiva costera del Reino de Granada (Rodríguez-Villasante, 2014; Sánchez, 2018). Desde la labor coordinadora como ente superior administrativo que realiza la Mancomunidad de Municipios de la Costa Tropical de Granada, se podría plantear la posibilidad de crear una oficina propia del historiador o investigador de carácter multidisciplinar dedicada esencialmente a la protección, promoción y puesta en valor de este amplio patrimonio científico de carácter defensivo, de una diversa y enriquecedora tipología y cronología (Gutiérrez y Riaño, 2018).

Con la finalidad de reducir o atenuar todas las anomalías o irregularidades ya comentadas anteriormente, se podría fomentar el acercamiento, conocimiento y difusión de este bien patrimonial a la sociedad de la que forma parte, proponiéndose actividades culturales de gran calado y seguimiento social como pueden ser las conferencias, exposiciones, actividades escolares o lúdicas que contribuyan a su divulgación y sensibilización. Y para ello partimos de la cita que dice: "Cuando se conoce lo que se ve, se empatiza con el entorno; lo que se comprende se quiere; lo que se quiere se protege, y lo que se considera propio se defiende" (Plan Nacional Arquitectura Defensiva, 2013).

Finalmente añadir que para el mejor desarrollo del presente trabajo de investigación, se ha hecho imprescindible emplear diferentes jornadas de campo que incluyeron la medición y la valoración tanto interna como externa de las posibles transformaciones experimentadas en la torre del Zambullón y de su entorno más inmediato, del que formó parte como pieza fundamental del sistema defensivo. Las fuentes documentales consultadas y recogidas en el apartado de referencias, ratifican su importancia que se extendió durante siglos principalmente en su misión de la protección del puerto de Calahonda.

Ya en la fase de laboratorio, se compararon los datos aportados de la jornadas de campo con las conclusiones alcanzadas del análisis de la planimetría de la época, adaptándolas a planos en formatos editables (AutoCAD), que permitieron realizar posteriormente una simulación de la perspectiva y recreación virtual que podría representar esta fortaleza durante el periodo de su máxima operatividad, coincidiendo con aquellos años que se pudo convertir en una torre con batería para la incorporación de dos cañones de artillería (Figuras 15-19). 
Figura 15. Sección y planta de la torre batería del Zambullón

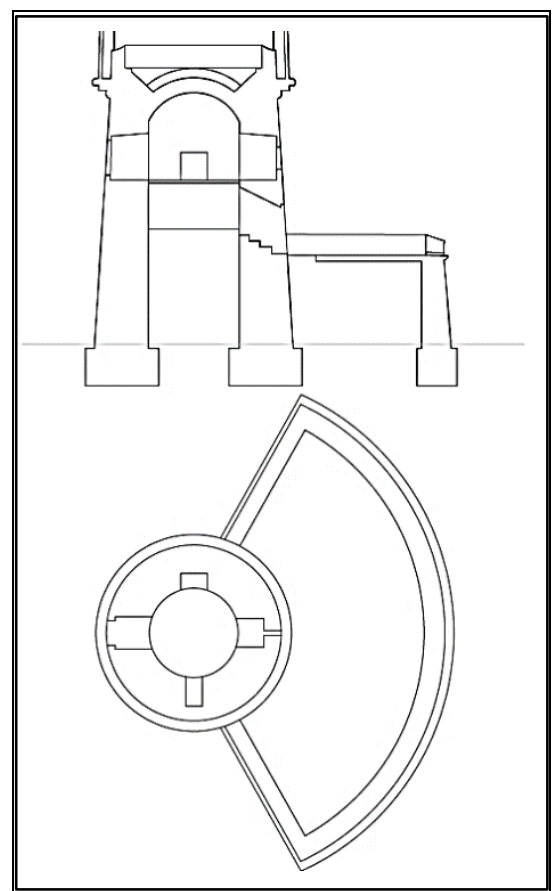

Fuente: Elaboración propia.

Figura 16. Planta acotada de la torre batería del Zambullón

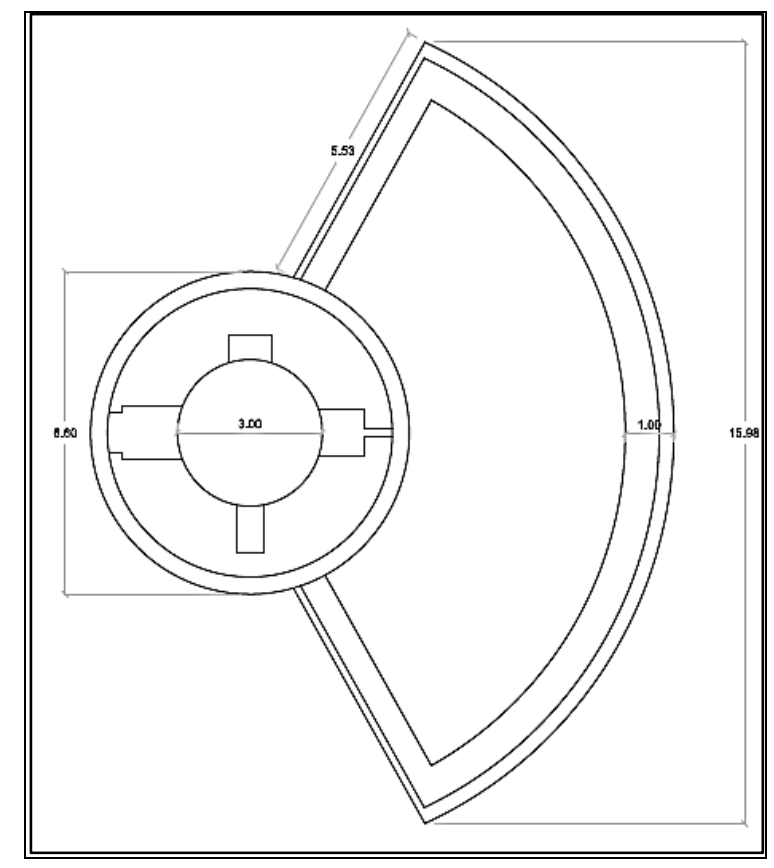

Fuente: Elaboración propia. 
Figura 17. Sección acotada de la torre batería del Zambullón

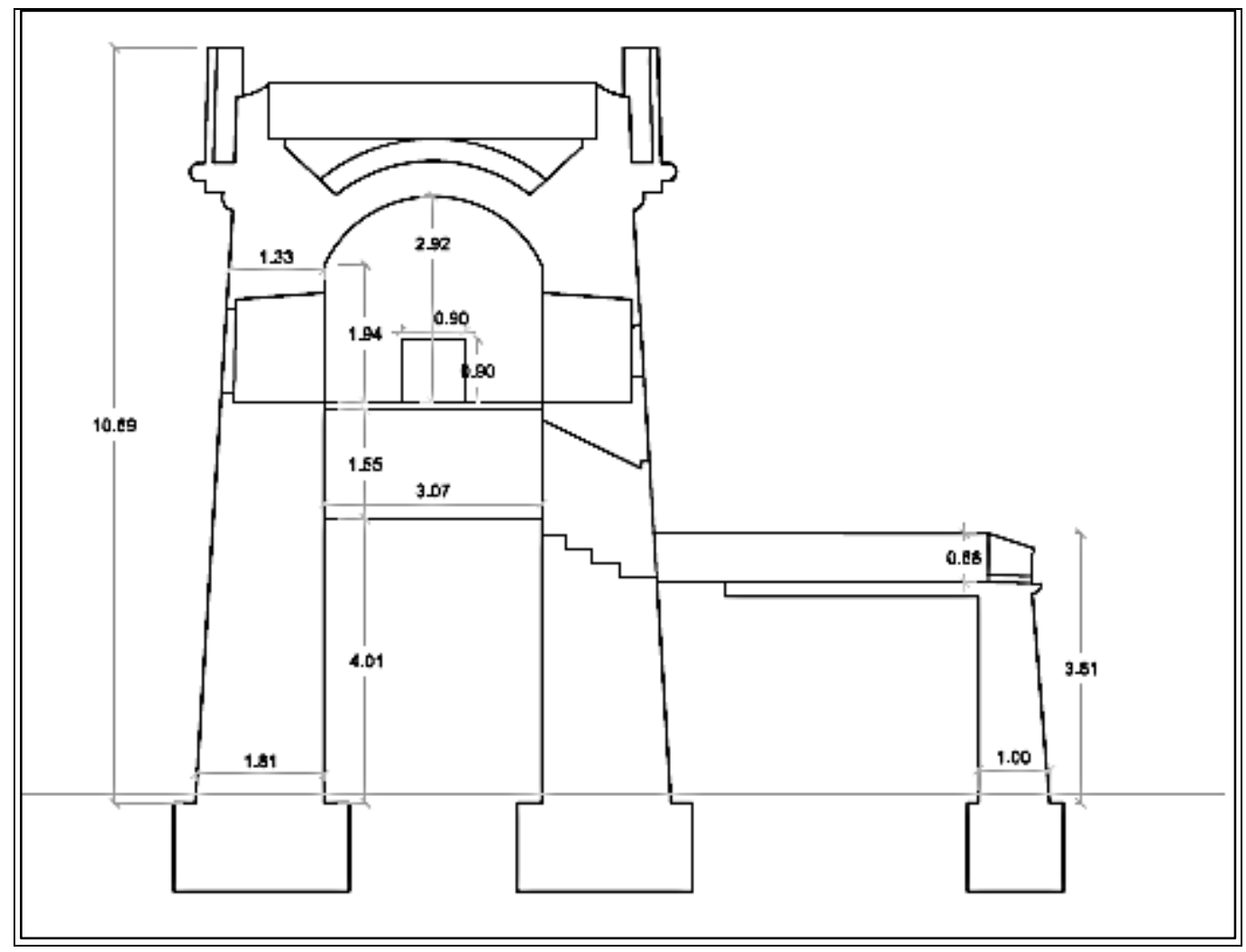

Fuente: Elaboración propia.

Figura 18. Simulación de una posible proyección de la planta de la torre batería del Zambullón

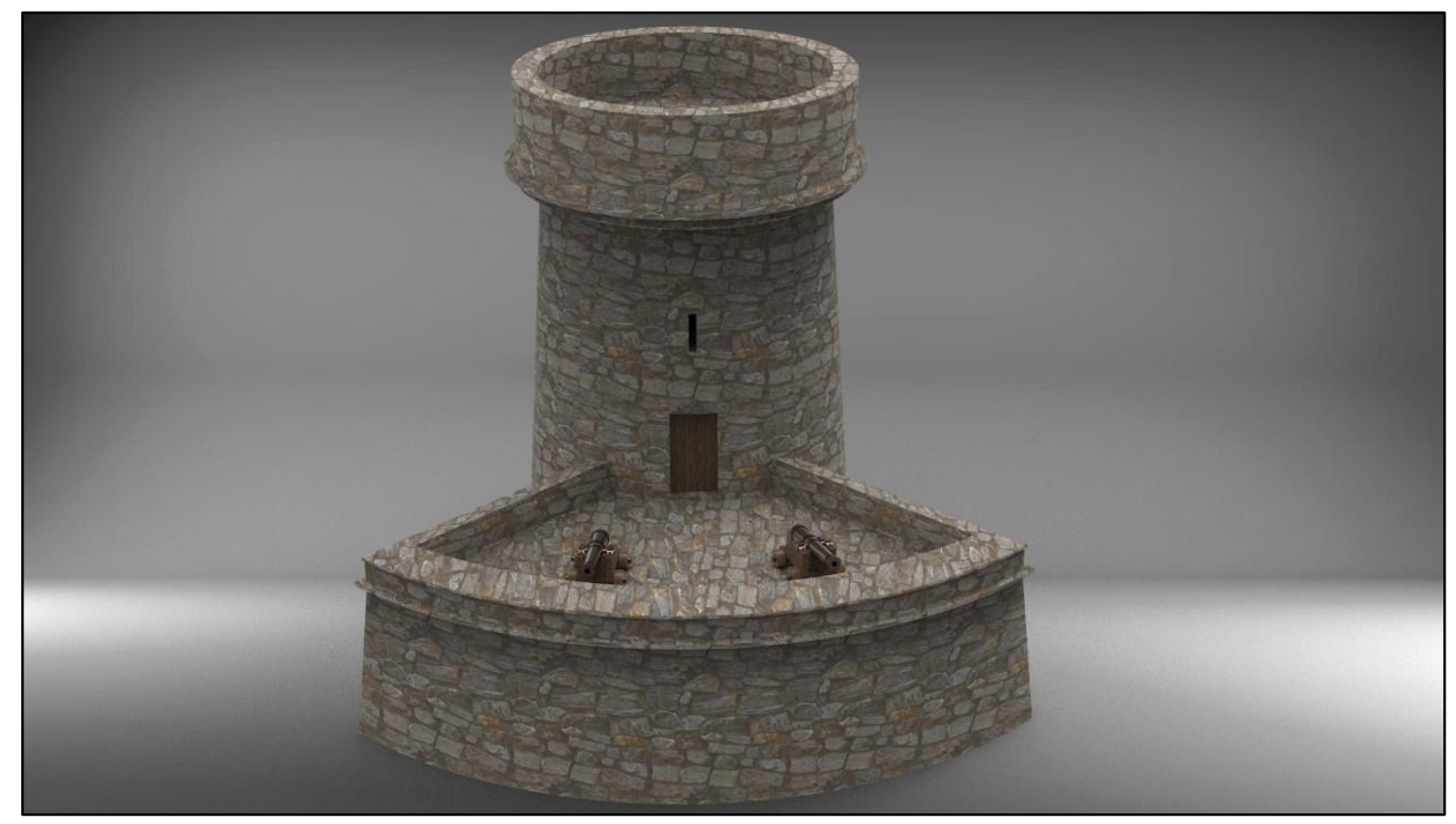

Fuente: Elaboración propia. 
Figura 19. Simulación de una posible proyección de la planta de la torre batería del Zambullón

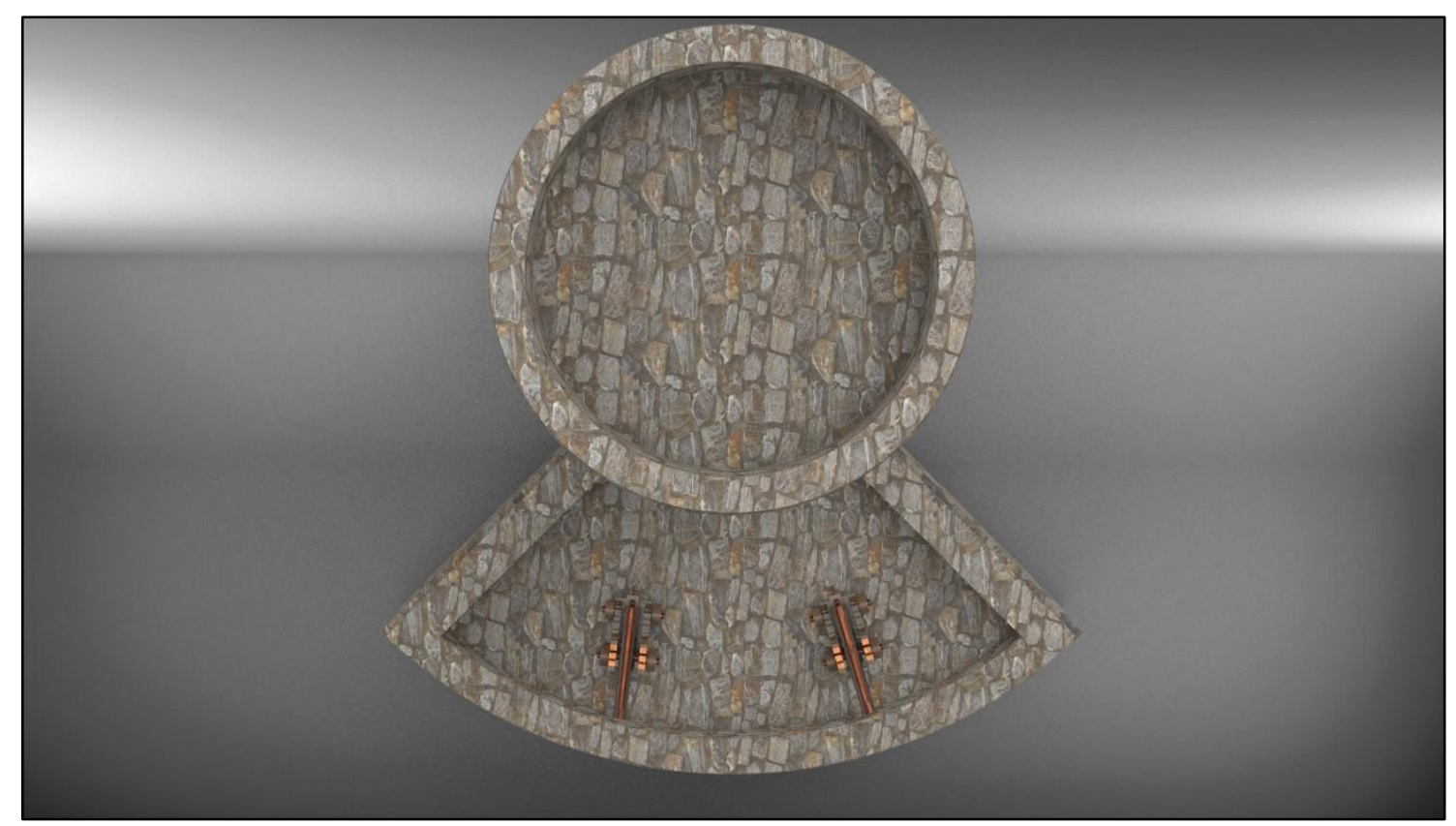

Fuente: Elaboración propia.

\section{AGRADECIMIENTOS}

Expresar mi gratitud a D. Rafael Maldonado Martínez y D. Francisco Javier Moreno Mendoza por su asesoramiento y colaboración en el diseño de la proyección de la torre batería del Zambullón.

\section{REFERENCIAS}

Baena, J. M. (2001). Dos propuestas de itinerarios culturales en Andalucía Occidental sobre Arquitectura Militar. PH: Boletín del Instituto Andaluz del Patrimonio Histórico, 9(36), 211-215. Recuperado de: https://www.iaph.es/revistaph/index.php/revistaph/article/view/1238 (20/05/2020).

Ballart, J., y Jordi Juan, J. (2001). Gestión del patrimonio cultural. Ariel.

Barceló de Torres, E., Barceló de Torres, I., y Álvarez García, Mª. M. (2014). Obras de consolidación y restauración del Castillo de Ucero (Soria). Patrimonio Cultural de España, (9), 227-240. Recuperado de: https://sede.educacion.gob.es/publiventa/detalle.action?cod=20115C $(15 / 05 / 2020)$.

Cobos, F. (2014). Fuentes de estudio y valoración de la arquitectura defensiva. Patrimonio Cultural de España, (9), 141-158. Recuperado de: https://sede.educacion.gob.es/publiventa/detalle.action?cod=20115C (15/05/2020). 
Fernández de Paz, E. (2006). De tesoro ilustrado a recurso turístico: el cambiante significado del patrimonio cultural. Pasos, Revista de Turismo y Patrimonio Cultural, 4(1), 1-12. https://doi.org/10.25145/j.pasos.2006.04.001

García-Consuegra, J. Ma (2017). Un museo al aire libre desaprovechado. El sistema defensivo de la Costa Tropical granadina en Época Moderna. Una visión global de las estrategias defensivas contra piratas y corsarios. Bastetania, Revista de Estudios de Arqueología Bastetana, (5), 61-87. Recuperado de: http://bastetania.ceab.es/wpcontent/uploads/2018/01/03-un-museo.pdf (01/03/2020).

Gil Albarracín, A. (2004). Documentos sobre la defensa de la costa del Reino de Granada (1497-1857). Ed. Almería.

Gómez Becerra, A., y Fábregas García, A. (1996). La costa de Granada. El territorio y la vida marítima. De la prehistoria al Siglo de las Luces. El puerto de Motril. Comares.

Gómez-Solórzano, L. S., Sancho Comins, J., y Bosque Sendra, J. (2018). Atlas temáticos y difusión del patrimonio cultural: Aproximación conceptual y aplicación al caso del centro histórico del distrito central de Tegucigalpa (Honduras). Boletín de la Real Sociedad Geográfica, (CLIII), 149-182. Recuperado de: https://www.boletinrsg.com/index.php/boletinrsg/article/view/61 (21/05/2020).

Jabaloy Sánchez, A., Galindo-Zaldívar, J., y Sanz de Galdeano, C. (2008). Guía geológica: Granada. Guías de la Naturaleza. Diputación de Granada.

Lorenzo Moreno, A., y Ayala Carbonero, J. J. (2006). El hombre y el medio. Monografías Ambientales de la Costa Granadina, (4), 139-159.

Gutiérrez González, Ma . E., y Riaño San Marful, P. A. (2018). Conservación y reuso de dos fortalezas habaneras: Atares y el Principe. Congreso Internacional ICOFORT 2018, San Fernando de Figueras (Gerona), pp. 388-420.

ICOFORT (International Scientific Committee on Fortifications and Military Heritage) (2018). Carta sobre fortificaciones y patrimonio vinculado. Pautas para la protección, conservación e interpretación. Congreso Internacional ICOFORT 2018, San Fernando de Figueras (Gerona), pp. 582-610.

Mata Olmo, R. (2008). El paisaje, patrimonio y recurso para el desarrollo territorial sostenible. Conocimiento y acción pública. ARBOR Ciencia, Pensamiento y Cultura, 184(729), 155-172. https://doi.org/10.3989/arbor.2008.i729.168

Martínez López, D. (1992). El ferrocarril Granada-Motril. Una vieja aspiración (18621948). Monografías de la costa granadina.

Morère Molinero, N. (2012). Sobre los itinerarios culturales del ICOMOS y las rutas temáticas turístico-culturales. Una reflexión sobre su integración en el turismo. Revista de Análisis Turístico, (13), 57-68. Recuperado de: https://aecit.org/jornal/index.php/AECIT/article/view/122 (20/05/2020).

Plan Nacional de Arquitectura Defensiva (2006). Ministerio de Educación, Cultura y Deporte.

Plan Nacional de Arquitectura Defensiva (2013). Ministerio de Educación, Cultura y Deporte.

Posadas López, E. J. (1996). La frontera marítima de Granada. Ed. Sa Nostra. 
Rodríguez-Villasante Prieto, J. A. (2014). El sistema estratégico y los conjuntos orgánicos de las construcciones defensivas. Patrimonio Cultural de España, (9), 61-67. Recuperado https://sede.educacion.gob.es/publiventa/detalle.action?cod=20115C

de:

Rubiella Romañach, A. (2014). Arquitectura defensiva o ingeniería militar, unas reflexiones. Patrimonio Cultural de España, (9), 29-47. Recuperado de: https://sede.educacion.gob.es/publiventa/detalle.action?cod=20115C

Ruíz Ortega, J. L. (2004). Patrimonio y desarrollo local en Andalucía. Boletín de la A.G.E., (38), 101-114. Recuperado de: https://bage.agegeografia.es/ojs//index.php/bage/article/view/484/0 (19/05/2020).

Sánchez Holgado, J. R. (2015). Las torres y atalayas de la Costa Tropical. ¿Un recurso turístico pendiente de explotación? Revista Espacio, Tiempo y Forma Serie VI Geografía, (8-9), 269-286. Recuperado de: http://revistas.uned.es/index.php/ETFVI/article/view/16365 (10/05/2020).

Sánchez Holgado, J. R. (2018). Paisajes y elementos de defensa y control del territorio en la Costa Tropical de Granada. Conservación y uso turístico de su patrimonio cultural de carácter militar (Tesis doctoral). Universidad Nacional de Educación a Distancia.

Silva Pérez, R., y Fernández Salinas, V. (2008). El patrimonio y el territorio como activos para el desarrollo desde la perspectiva del ocio y del turismo. Investigaciones Geográficas, (46), 69-88. https://doi.org/10.14198/INGEO2008.46.04

Velasco Hernández, F. (2019). Corsarismo, piratería y guerra costera en el sureste español. El acoso turbo berberisco a las costas de Alicante, Murcia y Almería en los siglos XVI y XVII. Ed. Nova Spartaria.

Zárate Martín, M. A. (2018). Presentación del número monográfico del boletín de la Real Sociedad Geográfica sobre "Geografía y patrimonio cultural". Boletín de la Real Sociedad Geográfica, (CLIII), 7-10. Recuperado de: https://www.boletinrsg.com/index.php/boletinrsg/article/view/54 (19/05/2020),

Documentos de archivos:

Archivo General de Simancas:

- G.A.: Leg. 74, d. 120. Gil Albarracín 2004 a, 579.

- C.C.: Leg. 2177, s.n. Gil Albarracín 2004 a, 601.

- G.M.: Leg: 3686, s.n. Gil Albarracín 2004 a, 657.

- G.M.: Leg. 3415, s.n. Gil Albarracín 2004 a, 747.

- G.M.: Leg. 3687, s.n. Gil Albarracín 2004 a, 785.

- G.M.: Leg. 3419, s.n. Gil Albarracín 2004 a, 833.

- G.M.: Leg. 3421, s.n. Gil Albarracín 2004 a, 855.

- G.M.: Leg. 3424, s.n. Gil Albarracín 2004 a, 883.

- G.M.: Leg. 3429, s.n. Gil Albarracín 2004 a, 893.

Instituto de Historia y Cultura Militar: 
- C.G.D.: Leg. 4-5-2-3. Gil Albarracín 2004 a, 671.

- C.G.D.: Leg. 4-5-2-5. Gil Albarracín 2004 a, 911.

- C.G.D.: Leg. 4-5-2-11. Gil Albarracín 2004 a, 933.

- C.G.D.: Leg. 4-5-2-14. Gil Albarracín 2004 a, 989.

- C.G.D.: Leg. 5-5-12-2. Gil Albarracín 2004 a, 1059. 


\section{EXTENDED ABSTRACT ${ }^{20}$}

Taking into account the repercussion of the territorial heritage as a main source of local and regional exploitation, the possibility of restoring the Zambullón Tower has been analysed. Keeping in mind its age and its interesting past, it could become an asset of cultural interest of Granada coast. In this way, Zambullón Tower contributes to the sustainable territorial development.

In order to do so, it was essential to know the geographical and historical context in which the Zambullón Tower is located, carrying out an extensive collection and a deep cartographic and documentary analysis that takes place between the 16th and 19th centuries. We would continue with a current valuation of the conservation status, and we would present some general intervention proposals and some conclusions.

In order to achieve an ideal development of this research, it was first of all indispensable to set different research periods that included the measurement and evaluation, both internally and externally, of the possible transformations experienced in the Zambullón Tower and its immediate surroundings, of which it took part as a fundamental element of the defensive system. The documents consulted confirm that its importance extended over centuries, with greater emphasis on the objective of protecting the port of Calahonda.

After an interesting laboratory phase, the data provided from the research periods were compared with the conclusions from the analysis of the planimetry of the time. These were adapted to blueprints in editable formats (AutoCAD). Later, the plans allowed a simulation of the perspective and virtual recreation that could represent this fortress during the period of its maximum effectiveness, coinciding with those years when it could be converted into a tower with a battery for two artillery cannons.

The main results show that from the 16th century the pier and subsequent dock, protected from the East winds, located near the cliffs of Calahonda beach, could become the main point of access and communication by sea of Granada coast. For this reason, the successive people responsible for the design and permanence of the defence system of the Kingdom of Granada gave it a special significance.

Since then, due to its location and task in the custody of this coastal strip and especially in the port of Calahonda, the Zambullón Tower was readjusted to the different defensive needs that during the period of its maximum effectiveness included the incorporation of a battery to the primitive defensive tower, which enabled to include artillery with the disposition of two cannons.

Recent visits made during the preparation of this research study have shown that, unfortunately, this asset of cultural interest has been abandoned to its fate, isolated on the same edge of the cliffs that it guarded for so many years, in a continuous process of advanced deterioration caused by the lack of any use and social recognition.

Owing to this fact, some general intervention proposals have been presented. Firstly, they are directed towards the recovery of this patrimonial element, having in mind another recovery strategies carried out in the same region as well as the important citizen engagement.

Aware of the importance of the promotion provided by the latest information technologies, their presentation and social participation will contribute to increase their

20 Traducción exclusiva del autor. 
recognition. Thus, its conservation and a necessary use adapted to the contemporary social requirements will be simultaneously favoured.

It would therefore be essential to reintegrate Zambullón Tower into the geographical space of which it forms part, thereby giving character to the territory and contributing to the creation of landscape.

As a conclusion or final reflection, it should be added that with an immediate recovery involving an appropriate restoration work, it would be possible to enjoy a unique example of military architecture of the coast of Granada. This fact would allow local population to strengthen its bonds with the nearest heritage, being aware of the prestige of having such a unique element of this complex defensive system. This scenario could favour territorial development on a local and regional level with some promotion and dissemination in accordance with its magnitude. 